\title{
Digital Aerial Photogrammetry for Updating Area-Based Forest Inventories: A Review of Opportunities, Challenges, and Future Directions
}

\author{
Tristan R. H. Goodbody ${ }^{1} \cdot$ Nicholas C. Coops ${ }^{1} \cdot$ Joanne C. White ${ }^{2}$
}

Published online: 20 March 2019

(C) The Author(s) 2019

\begin{abstract}
Purpose of Review Three-dimensional (3D) data on forest structure have transformed the level of detail and accuracy of forest information. While these 3D data have primarily been derived from airborne laser scanning (ALS), there has been growing interest in the use of 3D data derived from digital aerial photogrammetry (DAP) and image-matching algorithms. In particular, research and operational forestry communities are interested in using DAP data to update existing ALS-derived enhanced forest inventories. Although DAP depends on accurate terrain information provided by ALS to normalize digital surface models to heights above ground, in an inventory update scenario, DAP data currently have cost advantages over repeat ALS acquisitions. Recent Findings Extensive research across a broad range of forest types has demonstrated that DAP data can provide comparable accuracies to ALS for estimating inventory attributes such as volume, basal area, and height when used in an area-based approach with co-located ground plot information.

Summary Herein, we review research relevant to the use of DAP for updating area-based forest inventories in subsequent inventory cycles, highlighting issues and opportunities for DAP data in this context. We examine the use of DAP for areabased forest inventory applications, comparing data inputs, algorithms, and outcomes across numerous studies and forest environments. Lastly, we outline outstanding research gaps that require further inquiry including benchmarking of acquisition parameters and image-matching algorithms.
\end{abstract}

Keywords Digital aerial photogrammetry · Image-matching · Airborne laser scanning · Forest inventory update · Digital stereo imagery $\cdot$ Forest structure $\cdot$ Image based point clouds

\section{Introduction}

It is well known that forests are highly dynamic ecosystems that are perpetually undergoing successional changes through

This article is part of the Topical Collection on Remote Sensing

Tristan R. H. Goodbody

goodbody.t@alumni.ubc.ca

Nicholas C. Coops

nicholas.coops@ubc.ca

Joanne C. White

joanne.white@canada.ca

1 Faculty of Forestry, University of British Columbia, 2424 Main Mall, Vancouver, BC V6T 1Z4, Canada

2 Canadian Forest Service (Pacific Forestry Centre), Natural Resources Canada, 506 West Burnside Road, Victoria, BC V8Z 1M5, Canada growth and natural disturbance $[1,2]$. The provision of accurate and up-to-date forest inventories is essential to facilitate datadriven, effective, and well-informed forest management scenarios as well as formulate effective forest policy. High up-front inventory costs, complexity in data acquisition, and ongoing uncertainty surrounding the future state and condition of forests due to climate change are principle motivators for enhancing and modernizing forest inventory frameworks globally [3-5]. As with other resource management fields, the demand for, and expectations of, inventory quality and content have compounded. The inherent complexity of forest ecosystems incentivizes the argument that routine data acquisitions to update inventories are needed to capture and integrate these changes in order to increase knowledge of forest dynamics, improve forest stewardship, and ultimately provide data-driven justifications for forest and environmental policy [6-8].

To enhance inventory data content, the inclusion of structural characterizations of forests using technologies such as 
airborne laser scanning (ALS) with the goal of linking structure with standard forest inventory attributes such as height [9], volume [10], and basal area [11] is becoming widespread in research and operational forestry [12]. Linking ALS data in the form of spatial and structural information with traditional forest inventory plot data in the area-based approach (ABA) has brought about a paradigm shift in the conceptualization and implementation of forest inventories [13, 14]. Technological innovations such as ALS have been used to enhance forest inventory value through improvements in measurement and prediction efficiencies [15•], cost-effectiveness [16], and provision of a diverse and ever-increasing compilation of inventory data [17], model predictions [18], and finalized mapping products [19]. Inventory frameworks incorporating these data sets can be referred to as enhanced forest inventories (EFI) [20-23]. Alam et al. [24], who outline the economic impact of an EFI in Ontario, Canada, found that these data help to maximize the total value of wood fiber through proper product allocation, reduce fluctuations in raw wood fiber supply, and minimize inventory carrying costs and lost sales.

As opposed to traditional forest inventories, EFIs provide an abundance of advantageous, non-traditional information, such as structural forest characterizations that can be utilized to better inform forest management practices. Acquisition of ALS data with the intention of generating EFIs has become more common globally as a result of improvement in sensor specifications, quality of data sets, and innovative forest management research. ALS data sets are increasingly becoming adopted and utilized in industrial forest management as a method for enhancing inventory content, as well as bridging gaps between strategic, tactical, and operational levels $[20,25]$. Integrating ALS into inventories has been demonstrated to provide multi-scale information to improve ecological understanding and guide forest planning and management activities [15•, 26-28]. Likewise, these data sets can be joined with existing inventory frameworks to establish of EFI baselines. These baselines describe the initial state of the forest for use as inputs for future predictions, as well as a reference to evaluate management prescriptions [6].

One challenge related to the use of ALS within an EFI framework is how these data maintain their utility as they age. McRoberts et al. [16] found that the shelf-life of ALS datasets used in a model-assisted framework is at least 10 years, helping to reduce long-term inventory costs, as well as to maintain the accuracy and applicability of predictive attribute models. Fekety et al. [29] likewise demonstrated the temporal transferability of the ABA, and how pooling data across time increases their availability for improving inventory predictions. This indicates that ALS data can provide lasting value related to the landscape-level quantification of forest attributes, as well as immediate cost savings through the provision of high-quality digital terrain models (DTM).

While these data provide obvious quantifiable benefits to inventory systems, reliance on a single ALS data acquisition does not provide information on how forest vegetation is changing through time, perhaps one of the most critical long-term forest management directives [30]. Given the current unreasonable economics of repeat ALS data acquisitions, alternate technologies must be integrated to provide a means of cost-effectively and efficiently updating pre-established EFIs [20, 31, 32].

A technology that has garnered significant interest due to its similarities with ALS is digital aerial photogrammetry (DAP) $[33 \bullet \bullet, 34 \cdot \bullet$ (Fig. 1). The incorporation of DAP data for enhancing forest inventories is logical for a number of reasons:

- Stereo-photogrammetry has a long-standing history in forest management in general [35], enabling characterization of terrain, forest cover, and species data, amongst others $[20,36]$.

- The use of aerial imagery in forest inventory programs has a long history [37], extending almost a century in Canada [38]. Manual photo-interpretation of inventory attributes has been a primary data source for forest inventories since the $1950 \mathrm{~s}$ $[39,40]$; however, reliance on manual photo-interpretation is decreasing due to a lack of skilled interpreters and improvements in semi-automated and automated approaches.

- The advent of ALS data in the late 1990s challenged the utility of aerial photography as the data source of choice for forest applications [41]; however, renewed interest and investment in photogrammetry has occurred largely as a function of new capacity to derive $3 \mathrm{D}$ information that is similar to that of ALS data at a lower cost $[42,43 \cdot \bullet]$.

- The historical prominence and ongoing development of photogrammetry in the field of forestry, and resources management more generally, provide structural, spatial, and spectral information for the purposes of enhancing and updating forest inventories [11].

The relative advantages of ALS and DAP were first summarized by Baltsavias [44••]. For DAP, key strengths continue to be the ability to acquire data from greater altitudes at faster speeds, thereby enabling data acquisition over substantially larger areas relative to that of ALS, for a fixed number of flying hours. As a result, DAP acquisition costs are estimated to be one-half to onethird less than that of ALS [33••, 43••]. Ultimately, the cost differential between DAP and ALS will vary depending on the size and complexity of the area to be flown and the data acquisition specifications (e.g., point density for ALS, across-track overlap for DAP). DAP workflows are becoming increasingly automated [45] and in many jurisdictions, photos are routinely acquired for other mapping projects (e.g., base mapping updates) [46], further underwriting the costs of data acquisitions. In addition, there are commonly more service providers for airborne imagery than ALS data and increased competition amongst providers also influences acquisition costs. 


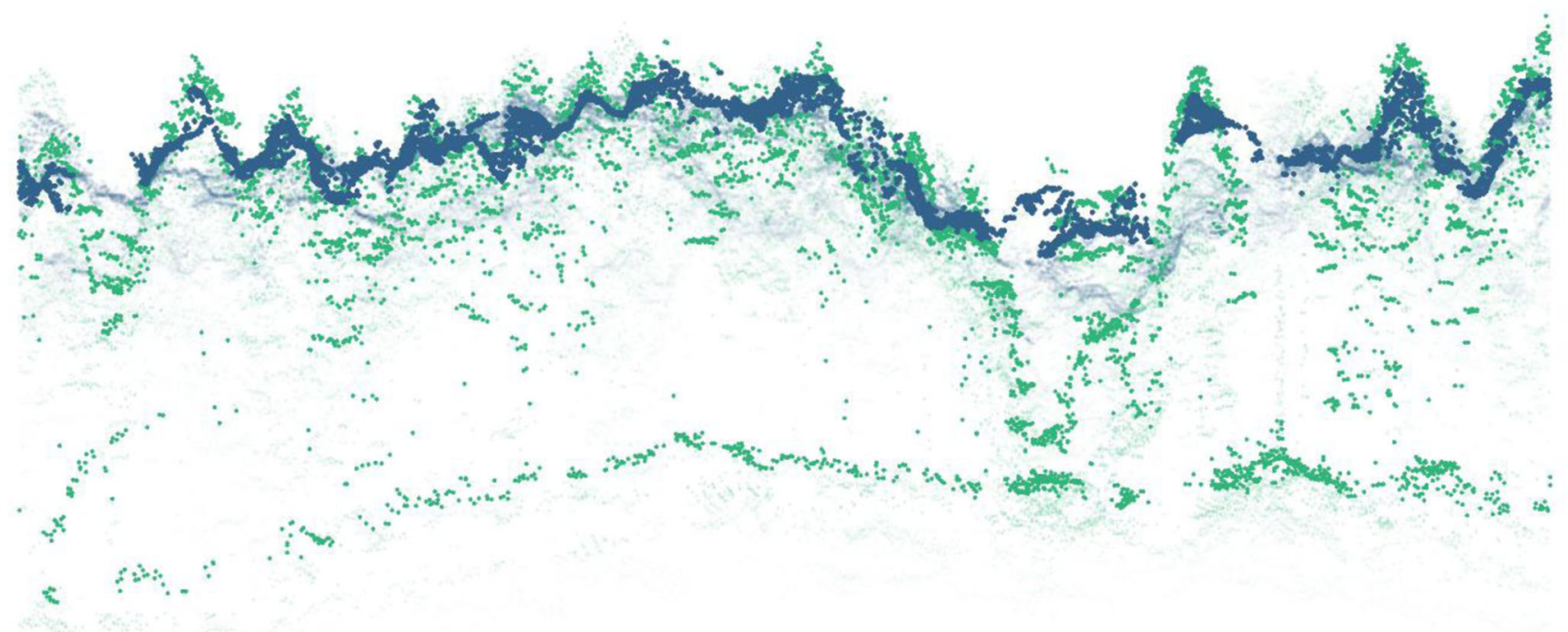

Fig. 1 Point cloud cross-section comparison of ALS (light green) and DAP (dark blue). ALS points can be seen characterizing internal forest structure and the ground surface, while DAP is limited to the outer canopy envelope

Key considerations are that acquisition and processing benchmarks have yet to be established, and that DAP is strongly influenced by shadows and occlusions from objects that can prevent image-matching. DAP's major difference from ALS in the context of EFIs is that it is limited to characterizing the outer canopy envelope (Fig. 1), as opposed to the vertical distribution of vegetation through the canopy profile [42]. DAP is however effective for conventional forest inventory processes such as manual interpretation tasks or stand boundary delineation, although options to automate these tasks are becoming increasingly viable.

In this review, we outline the role DAP has as a synergistic technology capable of integration into EFI frameworks. Our objective is to demonstrate that DAP data provide a viable source of information for updating EFIs. To do so, we first provide a background of digital photogrammetric approaches including notable acquisition parameters, DAP point cloud generation, and consequent point cloud processing. We then outline information needs for EFIs with a focus on the potential of DAP to be a successful data source within these frameworks. We then consider the role of DAP in the ABA [47] in estimating forest inventory attributes. Specifically, with reference to comparative literature, we outline the role DAP data sets can have as a tool for updating baseline ALS EFIs within the ABA framework. This synergistic EFI framework has the potential to reduce short- and long-term inventory costs, provide accurate and precise multi-scale data, and most importantly, be used to derive information on forest change through time to inform progressive socio-economic and environmental policy. It is our intention in this review to outline DAP's potential for integration into inventory systems to improve current practices, while also having the potential to improve efficiency, value, and the long-term viability of data products.

\section{Digital Aerial Photogrammetry}

DAP enables the generation of spatially continuous, 3D information derived from digital imagery datasets [43••]. Nomenclature for digital photogrammetric techniques and data have yet to be standardized, although DAP is acknowledged as a technology capable of characterizing certain components of vegetation structure in a manner analogous to ALS data $[31,42,43 \bullet \bullet, 48]$. The implementation of photogrammetric techniques to generate these $3 \mathrm{D}$ data is often referred to in the scientific literature as imagematching, 3D vision, or structure from motion, while terms to describe the $3 \mathrm{D}$ data itself have included image-based point clouds, image point clouds, photogrammetric point clouds, and digital stereo imagery, amongst others. Using photogrammetric principles in combination with digital imagery and computer vision algorithms, DAP measures the geometry of objects by projecting rays through stereo or multiple imagery to derive 3D features [36].

A digital photogrammetric system or framework is comprised of computer hardware and software designed to generate photogrammetric products from digital stereo-imagery using a combination of manual and automatic techniques. Rapid technological advancements and cost reductions for computer/platform hardware components have lowered the barriers-to-entry to conduct photogrammetric processing routines at spatial and temporal frequencies that were once costrestrictive [49]. Increased availability and cost-effectiveness of high-quality computer hardware has shifted the competitive edge of digital photogrammetry systems to being software driven with a variety of commercial and open source software available [50]. 


\section{Enabling Technologies}

Although digital frame scanners (area-array sensors) have been predominantly used for photogrammetric surveying, some linear-array architecture sensors, also known as pushbroom or three-line scanners (e.g., Leica ADS80), have shown promise for stereo image acquisitions [51, 52] (Table 1). These sensors incorporate forward-, nadir- and backward-oriented overlapping panchromatic scenes that allow derivation of 3D products [53]. Additional linear arrays have also been added to provide multispectral, as well as trueand false-color imagery [54]. Studies such as Haala et al. [55], which compared the ability of frame and pushbroom sensors to generate DTMs and ortho-imagery, found that both technologies are equally capable of generating accurate products and that the choice of sensor type is more dependent on overall hardware and software costs, as well as the performance of commercially available processing suites. In-depth summaries and examples of contemporary linear- and area-array sensors can be found in Lemmens [56] and Pepe et al. [51].

Digital sensors provide improved radiometric performance, eliminate film processing costs, physical storage space requirements, and facilitate highly automated workflows that greatly reduce the time needed to generate photogrammetric products [43••, 57]. Digital sensor technologies have also improved ground sample distances (GSD) and image capture rates. These technological advancements have increased the number and quality of images being acquired and consequently improved the potential for increased imagery overlaps. This means that more images are being acquired at no additional cost [58], improving rates of successful image matching and survey cost-effectiveness. Increased image overlaps can also reduce the required intensity of ground control due to reductions in systematic and pseudo-systematic errors influencing photogrammetric measurement accuracy [59]. It must be added that although increases in along-track overlap can be realized without any added cost to surveying [43・•], increasing across-track overlap would require more flight lines, driving up cost. This is why a high-overlap/flight efficiency tradeoff exists and must be balanced according to image parameter requirements.

Significant advancements in the quality and quantity of imagery through direct geo-referencing from high-quality onboard GPS-derived positions and inertial navigation systems (INS) have led to improved accuracy of photogrammetric processing [60]. Unlike frame cameras, linear-array systems must rely on GPS and INS systems for accurate position information. These components add cost to the overall image system $[61,62]$. These technological innovations have provided a means of generating high-density and accuracy point clouds for forest surveying [43••], while realized economic efficiencies can be attributed to imagery digitization.
Image-Matching Algorithms

Image-matching algorithms are diverse, with a variety of algorithms having been used to generate point clouds for the purposes of estimating structural attributes of vegetation and timber [9, 11, 47, 48, 63, 64]. Algorithms can be separated into two distinct streams, feature- and area-based methods [45, 65-67]. Feature-based methods, the simpler of the two types, use rudimentary cartographic points and lines to find image matches, while area-based methods use a moving window approach that analyzes pixel differences to find matching points [68]. A thorough history and description of the development, testing, and implementation of image-matching algorithms can be found in Remondino et al. [45, 69]. The performance of contemporary algorithms has invoked a renewed interest in aerial photography due to their provision of veryhigh-resolution imagery and structural information at a lesser cost than ALS [50].

Software robustness, reliability, and speed are a rapidly advancing field, increasing competition amongst software developers $[50,70,71]$. The proprietary nature of some algorithms, however, raises challenges related to their functionality, where "black-box" transparency restrictions limit knowledge of the assumptions of inner workings of the algorithms and reduce algorithm-focused reporting [69]. A secondary challenge in using these algorithms is that they have not been purposefully developed to reconstruct vegetation for forest inventory purposes [72], an area where continued research into algorithm refinement and benchmarking is warranted. The degree to which software can be parameterized is important for forest environments (amongst others). Parameters are often determined by trial and error and many are software specific. This poses challenges for large area implementations.

Many software packages implement some form of the semi-global matching (SGM) algorithm [70, 73]. SGM is a fast and efficient image-matching algorithm and has been demonstrated to provide accurate image-matching results with low processing times $[74,75]$. The inter-comparison of selected algorithms for the purposes of producing point clouds for forest attribute prediction has typically focused on a comparison of two software packages, rather than a systematic evaluation. Ullah et al. [48] and Kukkonen et al. [68] compared software in the context of the ABA for forest attributes, for canopy cover prediction by Granholm et al. [76], and for miscellaneous targets in Remondino et al. [45]. Both Ullah et al. [48] and Kukkonen et al. [68] found that data derived from image-matching techniques were capable of predicting forest inventory attributes with comparable accuracies to those from ALS, which is the consensus from other comparative analyses $[42,58,77]$. In Ullah et al. [48] the SGM algorithm was found to outperform the enhanced automatic terrain extraction (eATE) algorithm for generating information layers or thematic map products to aid forest management. SGM was found to 


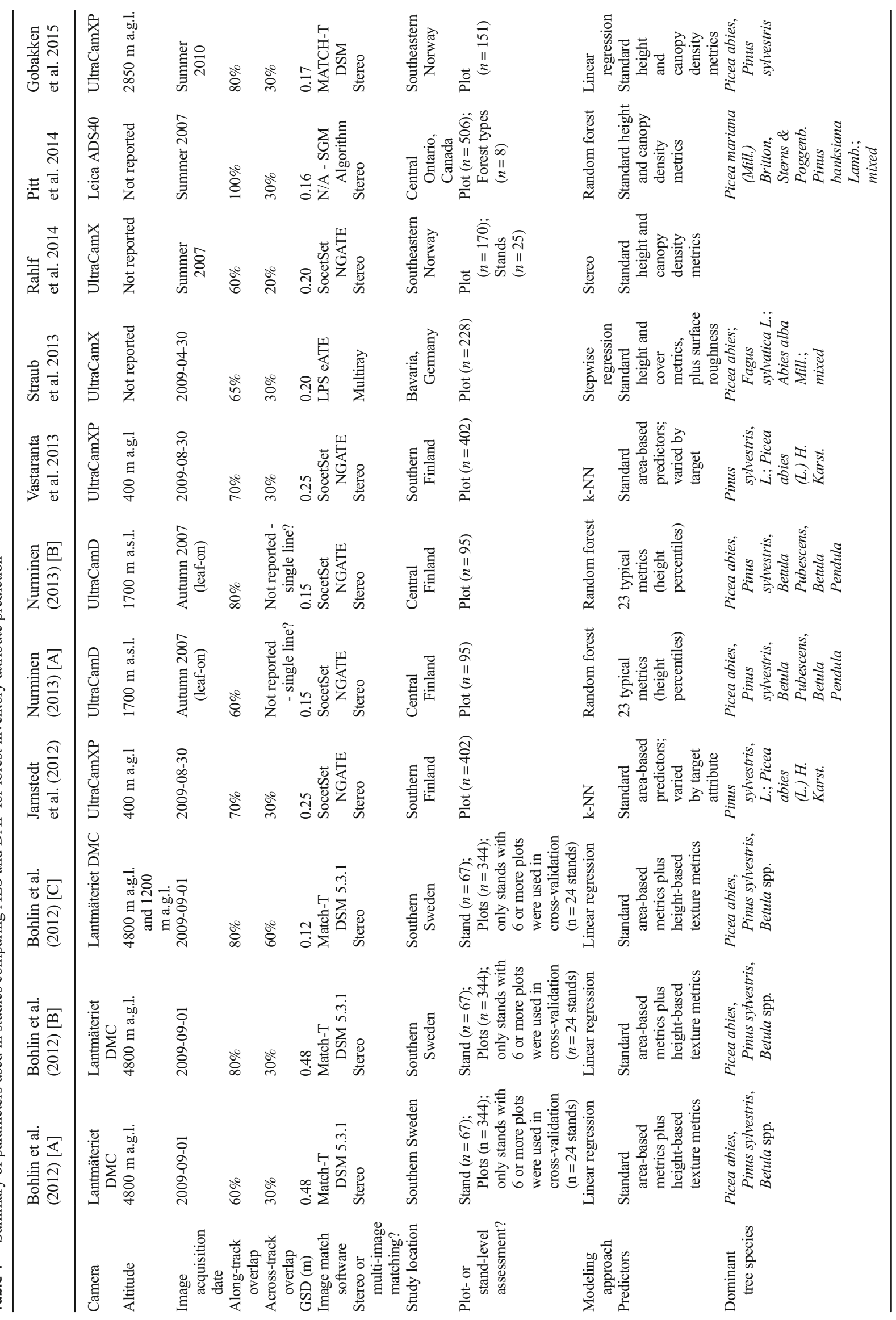




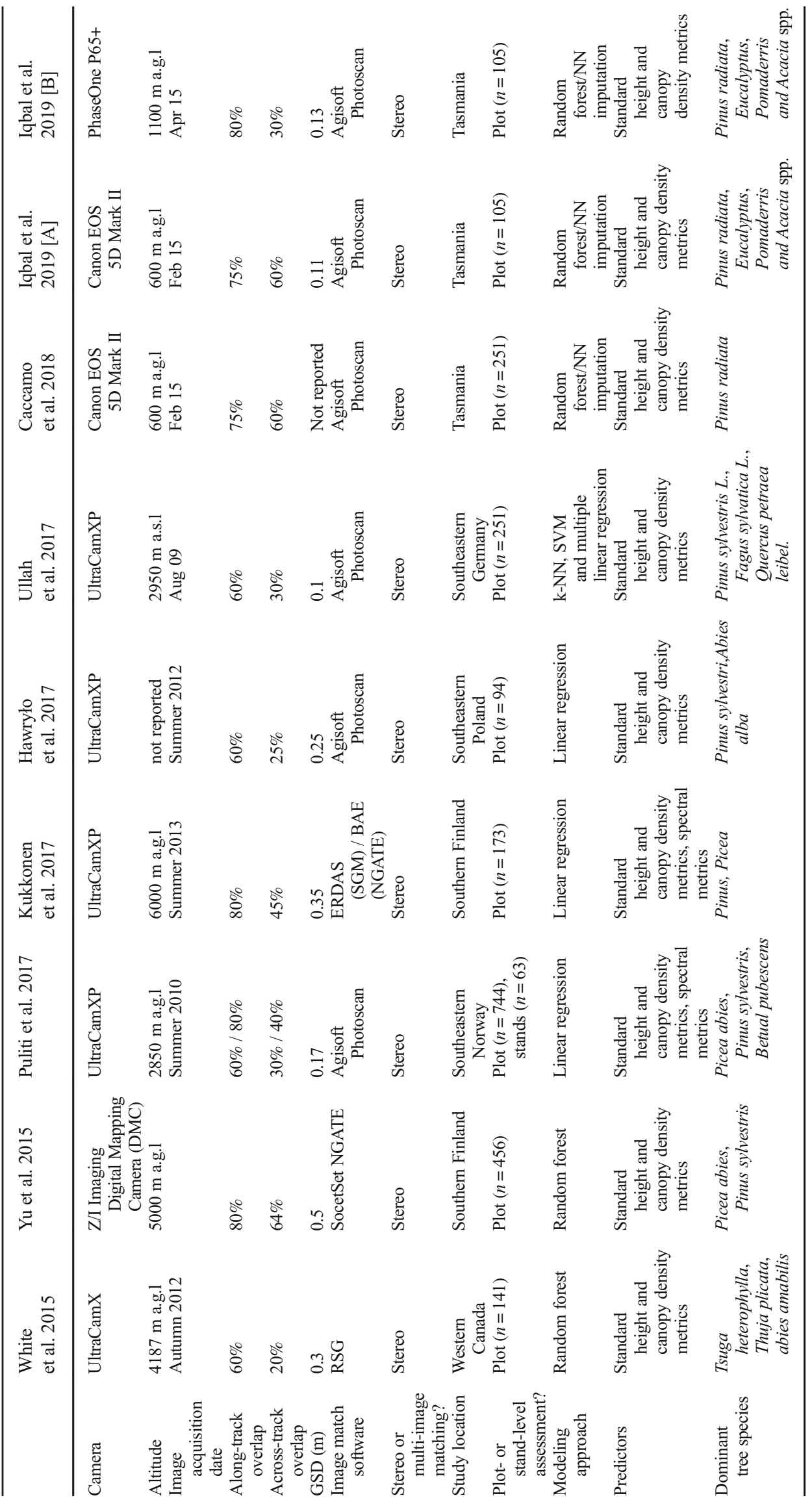


be the simpler of the two algorithms, with less user-defined parameters, produced denser point clouds $\left(\mathrm{SGM}=27.66 \mathrm{~m}^{-2}\right.$, eATE $=3.29 \mathrm{~m}^{-2}$ ) at faster processing speeds, and achieved slightly greater predictive model (multiple linear regression) accuracies $(\%$ RMSE SGM $=28.3$; eATE $=29.0), k-\mathrm{NN}$ $(\%$ RMSE SGM $=29.9$; eATE $=30.0)$, and SVM $(\%$ RMSE $\mathrm{SGM}=28.3$; eATE $=29.0)$ ). Kukkonen et al. [68] compared SGM to the next-generation automatic terrain extraction (NGATE) algorithm [78] for predicting a suite of forest attributes. They found negligible differences in generated digital surface models and indicated that both algorithms were capable, accurate, and consistent ( $\pm \sim 2 \%$ RMSE for all attributes) at providing forest attribute predictions with the pre-condition that an ALS DTM was available. Granholm et al. [76] compared the MATCH-T and SURE algorithms for estimating vertical canopy cover and found differences in point cloud outputs, but not in generated metrics. All studies, however, were cautious in their recommendation of a particular algorithm due to the potential differences that could arise from software tuning, forest type, and solar illumination.

\section{Digital Photogrammetric Workflow}

Prior to image acquisition and consequent photogrammetric processing, a number of factors must be considered for successful imagery acquisitions (Fig. 2). Mission planning in aerial photogrammetric projects is the primary and critical step to ensure success in consequent acquisition and processing stages [51]. Flight planning is likely the area that would most benefit from parameter benchmarking studies as it would help to improve overall cost-effectiveness and efficiency of acquisitions, while ensuring that consequent point cloud products are best suited to area-based predictions. Pepe et al. [51] provide an in-depth review of flight planning considerations for a variety of platforms and sensors, as well as commercially available and open source flight planning software. Similarly, Osborn et al. [79] detail photographic componentry and settings, imaging sensors and platforms, and flight planning details with their advantages and disadvantages for photogrammetric mapping to support forest inventories.

\section{Imagery Acquisition}

Landscape-level imagery acquisitions for the purposes of forest inventory-related photogrammetric analyses have been proven capable and effective for providing structural and

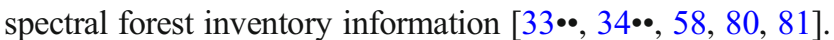
Aerial imagery acquisitions are often updated on a regular basis by national or regional mapping entities [46, 82], further underwriting the costs of using these data in forest inventories, and making aerial images a dependable data source with temporal depth [83]. Examples of jurisdictions with planned imagery acquisitions every 3-10 years include the United States of America (National Agriculture Inventory Program [84]), Finland (National Land Survey of Finland [85]), and Switzerland (Federal Office of Topography [86]). The utilization of these datasets, which are often widely available, could be a useful and cost-effective means for identifying and monitoring forest change, as well as realizing unforeseen inventory value.

Parameters of importance that have been tested in the literature that require continued benchmarking are flight altitude and GSD, across-track overlap, sensor type and model, and light conditions (Fig. 2). Standardization and benchmarking studies that focus on these key parameters are therefore crucial to detailing best practice approaches to image acquisition. Given that the updating of area-based EFIs is generally conducted at a landscape level, herein, we focus on the use of manned aircraft for image acquisitions and their capacity to cost-effectively acquire imagery over large spatial extents [43••]. We do however acknowledge the growing body of research using unmanned aerial systems (UAS) for imagery acquisition and EFI updates [87].

Altitude and GSD Bohlin et al. [34••] tested multiple configurations of altitude, image overlap, and GSD: 60\%/30\% overlap along- and across-track respectively with GSD $=0.48 \mathrm{~m}, 80 \%$ / $30 \%$ with GSD $=0.48 \mathrm{~m}$, and $80 \% / 60 \%$ with $\mathrm{GSD}=0.12 \mathrm{~m}$ (Fig. 5). The authors found that variation in GSD from lesser flight altitudes (e.g., $1200 \mathrm{~m}$ above ground level (agl) versus $4800 \mathrm{~m}$ agl) generated denser point clouds, but did not improve tree height, basal area, or stem volume estimates. Similarly to results found in Lim et al. [90] using ALS, Bohlin et al. [34••] concluded that plot-level variable prediction with DAP is robust, and that an increase in point density will not affect outcomes unless changes in forest structure occur. Honkavaara et al. [91, 92] found that GSDs of $30-40 \mathrm{~cm}$ provided surface models that adequately characterized leading forest cohorts. This could provide justification for increasing flight altitude to improve cost-effectiveness [58]. Gobakken et al. [93•], however, also highlight that the relationship between flight altitude, camera lens angle, and increasing GSD can result in a reduction in the accuracy of height predictions. Gobakken et al. [93•] note that while wide angle lenses provide increased overlap, especially at greater altitudes, that if image capture proximity is dispersed, point clouds will suffer from occlusion issues and become less accurate in estimating tree heights. This point was confirmed by Tanhuanpää et al. [94], who evaluated high altitude DAP data for individual tree detection. Furthermore, increased amounts of atmospheric noise at greater flight altitudes could increase error in estimates [93•]. Considerations regarding the need for point cloud completeness and height prediction accuracy should guide acquisition planning and imagery capture [95]. Järnstedt et al. [77] conclude that differing requirements for ALS and DAP with regard to flying altitudes and distances between flight lines is potential justification for using 
Fig. 2 Flowchart listing the order of a theoretical digital photogrammetric workflow with associated research gaps for each stage

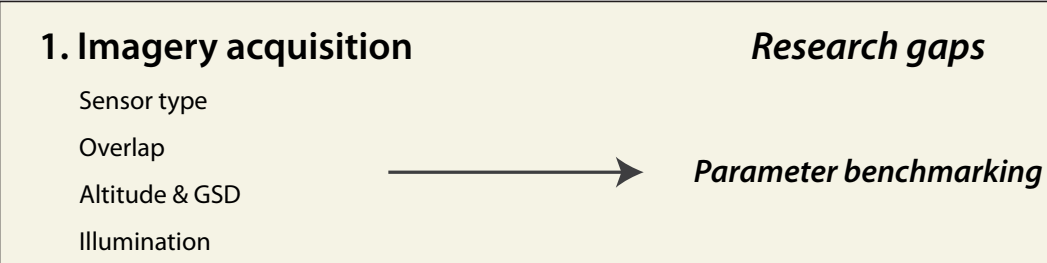

\section{Point cloud generation}

Image alignment

Key-point generation

Automatic tie-point generation

Point cloud densification

Algorithm benchmarking

\& forest type testing

3D textured mesh \& orthomosaic

\section{Point cloud processing}

.laz compression

Tiling

Noise filtering

Point classification

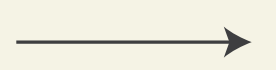

Establish standardized

DTM generation

processing streams

(Merge ALS ground points)

Normalization

Metric generation

\section{Area-based modelling}

Merge field measures

with co-located point cloud metrics

Establish modelling framework

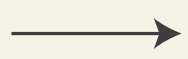

Apply attribute models

wall-to-wall
Assess model robustness

\& transferability imagery as a single data source to considerably improve inventory efficiency.

Image Overlap The most commonly used methods for planning imagery acquisitions involve flying in strips with a predetermined amount of along- and across-track overlap. Alongtrack overlaps between 60 and $80 \%$ are common for photogrammetric projects [36] (Table 1), with values of $80 \%$ and above being used for improved penetration between objects for more effective and accurate depth reconstruction [51], as well as to reduce the impact of shadows on image-matching algorithms [72]. Given that mission planning has generally focused on the acquisition of ortho-imagery products and not digital photogrammetric analyses, imagery overlap has generally been less than what is needed for complete point cloud derivation, potentially influencing area-based capabilities. With digital camera systems, an increase in along-track overlap comes at no cost [43••]. Several studies have demonstrated that an increase in along-track overlap from 60 to $80 \%$ reduces the relative RMSE for area-based attribute predictions [34••, 58, 96•]. This again however must take into account the trade-off that exists between image overlap, flight time, and increases in acquisition costs [97]. Pre-planning of the most effective and efficient overlap for the desired data quality is therefore of great importance for utility, efficiency, and budgetary reasons.

Straub et al. [46] concluded that imagery with overlaps of $65 \%$ and $30 \%$ along- and across-track respectively is sufficient to support stereo image-matching and area-based outcomes, noting that increased overlap would likely improve other applications, such as detection of canopy gaps. White et al. [98] compared the use of DAP and ALS data for canopy gap detection and mapping, concluding that point clouds generated from imagery with $60 \%$ along-track and $20 \%$ acrosstrack could not provide analogous results to those of ALS for detecting canopy gaps in coastal rainforests on Vancouver Island, Canada. Indeed, the majority of imagery used for generating DAP point clouds for forest inventory applications are acquired with along-track overlaps of $60 \%$ and across-track overlaps that range between 20 and $35 \%$ (Table 1), reducing the potential for multi-image matching. Further research into 
multi-image matching for reducing the influence of occlusions such as shadows in forest canopies is needed [58, 99••, 100]. UAS could provide a useful tool for benchmarking acquisition parameters and optimizing overlap scenarios in different forest types, as their ability to acquire imagery is fast, cost-effective, and can be parameterized to mimic aerial acquisitions [101].

Imaging Sensors Studies that have assessed the utility of DAP data for ABA have predominantly used large-format digital frame sensors (Table 1), although Pitt et al. [52] used a lineararray system. Nurminen et al. [58] outlined that flight efficiencies and significant cost-savings, likely related to greater detail and larger film surface, can be realized when using largeformat photogrammetric sensors. Straub et al. [46] found that the frame-array sensors can be used to model inventory attributes in more structurally complex forests. Iqbal et al. [89•] compared photogrammetric approaches using small- and medium-format digital camera systems. Their findings indicate that both systems provide similar predictive accuracies to those of ALS (Fig. 5), enabling forest managers to use data acquisition solutions that best fit their operational needs. Conclusions from these studies indicate that forest inventories supported by an accurate pre-existing ALS DTM can be updated using optical imagery from a variety of sensors.

Illumination Gobakken et al. [93•] indicated that large-area imagery acquisitions for the purposes of generating a DAP ABA inventory may be prone to varying illumination conditions such as sun angle, which have been shown to influence the geometric properties of the generated DAP canopy [72]. White et al. [42] and Rahlf et al. [102•], however, found that sun angle had minimal influence on ABA outcomes. Rahlf et al. [102•] found that including sun inclination as a predictor reduced the relative RMSE of area-based predictions by $\sim 2 \%$. Variation in lighting conditions during a single flight could also be considered rationale for not incorporating spectral metrics as explanatory variables within forest parameter models unless rigorous radiometric calibration is possible [102•]. Systematic testing of the potential utility and importance of spectral metrics for estimating speciesspecific forest variables and canopy health [103] could enhance forest management and planning [11, 34••, 68, 80, 96•].

\section{Point Cloud Generation}

Following acquisition and compilation, acquired imagery must be photogrammetrically processed. Images are first optimized and aligned using meta-data including internal sensor specific information such as the focal length and field of view, as well as image specific external data such as GPS location and IMU orientation. The inclusion of survey grade ground control locations during processing is also highly desirable [79]. Image key points, pixels, or areas of interest with high contrast or texture that are easily identifiable in image sets are then isolated within each image. The number of key points that are compiled for an imagery dataset is dependent on the size of the images as well as its visual content. A landscape largely covered in snow with little spectral variation will likely yield fewer key point matches than a spectrally variable landscape.

Key points are then matched amongst the image dataset and are consequently processed to derive their 3D location, which are labeled as automatic tie-points. Manual tie-points can also be added, which are user defined markers that are often used to assess and improve 3D reconstruction accuracy. The result of the initial tie-point generation produces a lowdensity DAP point cloud.

In order to increase the density of the output point cloud, automatic tie-point generation continues until pixel matching has reached a pre-determined limit, or is exhausted. Software packages generally have differing levels of automatic tie-point thresholds [104], which depending on available computational power increase the density of the output point cloud. The product following completion of densification is what will be exported and used for consequent point cloud analysis (Fig. 3). Generally, however, the densified point cloud is used to generate a 3D textured mesh, a structural surface with image inherited spectral data, which is often used for the creation of orthomosaics to remove perspective distortion from images and reflectance maps. The $3 \mathrm{D}$ textured mesh can also be described as a digital surface model (DSM).

\section{Point Cloud Processing}

Processing of densified DAP point clouds follows a similar stream to that of ALS. This is one of a number of reasons why the integration of DAP is logical for updating ALS-derived EFIs. Major processing steps can be conducted as follows; however, no common standards for point cloud processing have yet been established (Fig. 2).

Exported densified point clouds, which are often stored as uncompressed .las format files [105] are converted to compressed files (.laz) to improve processing speed and reduce digital storage requirements. This step is not mandatory; however, it is advisable as storage requirements can be reduced to $7-20 \%$ of original uncompressed file size [106]. Converted files are then subdivided into tiles with a pre-determined amount of overlap and processed individually to increase processing efficiency. Given that anomalies can occur in point cloud generation, tiles are filtered for noise that could introduce bias into future processing stages. Points within tiles are then classified into one of the ASPRS defined LAS classes [105], which distinguish between ground, vegetation, and water amongst others. Points classified as ground are isolated and can be used to generate DTMs [107].

A fundamental limitation of DAP data is its inability to produce accurate DTMs over areas of moderate to high canopy cover [108, 109]. DAP-derived DTMs from forested areas 




Fig. 3 Simplified visualization example of how DAP point clouds are generated from stereo imagery

are often inaccurate and are inadvisable as products for normalizing DAP point clouds to heights above ground level potentially leading to inaccurate area-based estimates (Fig. 4). Lack of the ability to provide accurate DTMs considerably limits the scenarios where DAP could be used to establish baseline EFIs. DTMs from other sources such as shuttle radar topography mission (SRTM) DTM products can be used [11]; however, these will not provide results with the same reliability and spatial accuracy as ALS DTMs, which are often considered best available data products, having the requisite spatial resolution and accuracy available under canopy.

To remedy the issue of poor DAP-derived DTM quality, co-located ALS-derived DTMs can be integrated into the DAP processing stream for point cloud normalization [33••, 34••, 58, 81, 99••]. Moreover, structural metrics derived from DAP point clouds that use the same terrain information for normalization to heights above ground readily facilitate multitemporal comparisons, while improving the long-term value of ALS acquisitions [34••, 42, 77, 93•].

\section{Forest Inventory Update: Information Needs}

Forest inventories have made significant progress in improving forest stewardship and sustainable practices and are heavily relied upon as planning and management tools for effective forest management operations [8]. Forest management information needs are increasingly complex and wide ranging: biodiversity, habitat and non-timber values, riparian management, evolving forest practices legislation, and climate change amongst others [110]. These needs place pressure on forest inventory programs to supply data that is timely, spatially detailed, accurate, and that characterizes forest composition, structure, and condition [111].

Globally, forest inventories at various spatial scales are continuing to shift toward multi-attribute, spatially-explicit polygon data derived from photo-interpretation and field measurement campaigns [30]. Conventional update methods have involved the acquisition of aerial photography and reconnaissance sketch mapping missions, satellite imagery, and field surveys [6]. Acquired inventory data and modeling outcomes focus on the provision of information on the current status, and projected condition of timber and non-timber resources. Wall-to-wall forest parameter estimates such as tree height, volume, basal area, growth and yield projections, and photo-interpreted imagery polygons are common [18, 27, 28, 112, 113].

While traditional methods have been effective, there are opportunities to modernize forest inventory frameworks [111]. Ensuring completeness and currency, as well as designing adaptable frameworks that facilitate the routine updating of previously acquired data is essential to enhancing inventory systems. In order to make the most informed and proactive management decisions, data being used should be as current as possible and aid in building on trends such as growth and yield [32]. The routine updating of inventories for the purposes of improving yield projections is critical to better understand stand growth and development patterns for formulating effective economic projections, understanding future socio-economic reliance on forest ecosystems, and forest policy. Organized monitoring and scheduled inventory updating can be used to have profound impacts on the long-term future projections of forest and timber attributes [6, 114, 115].

According to Gillis and Leckie [6], an inventory update is defined as the process of detecting, collecting, and adding 

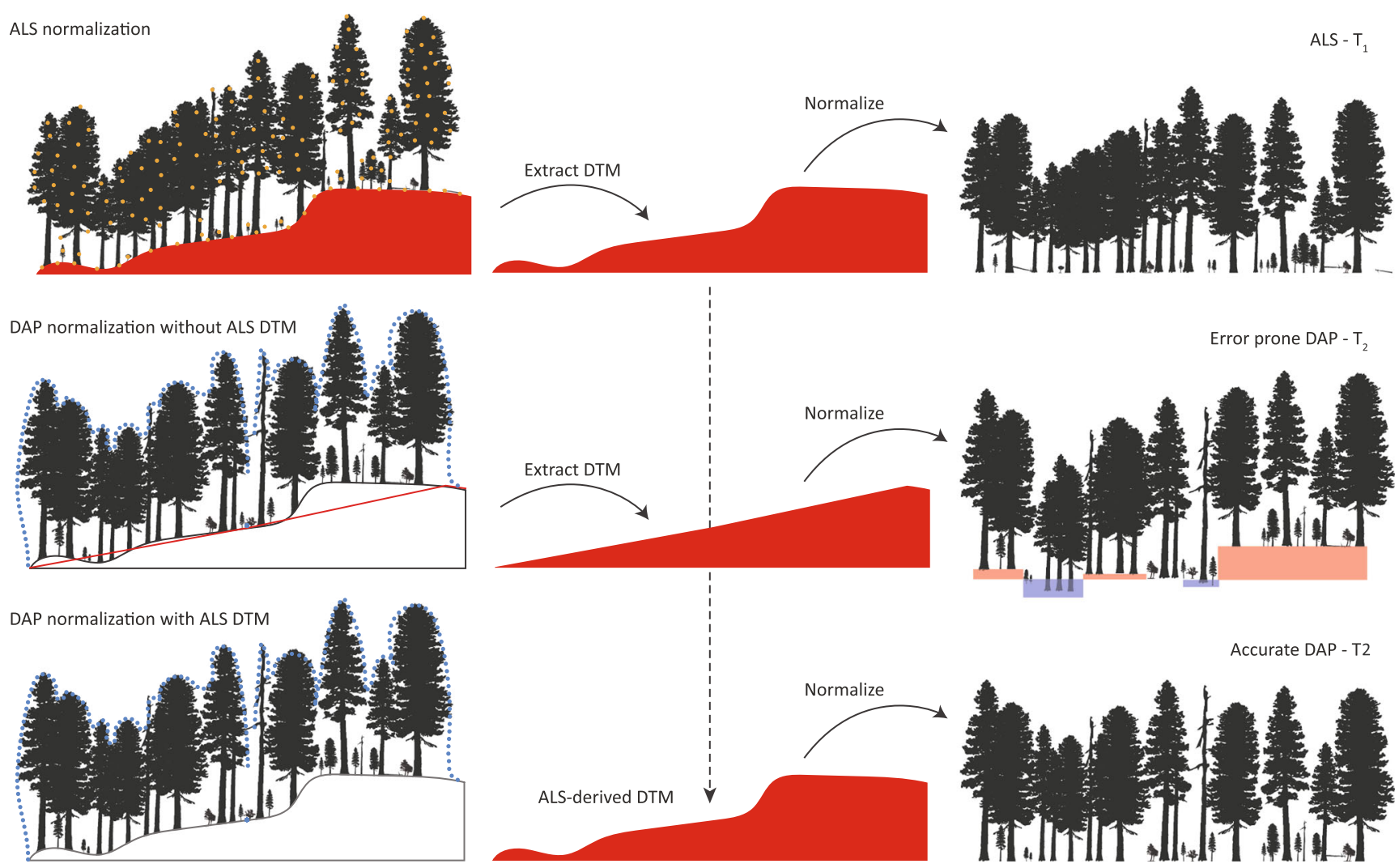

Fig. 4 Schematic visualizing how normalization of $T_{1}$ ALS and $T_{2} D A P$ point clouds is conducted. ALS data is normalized using points classified as ground (top) to remove terrain influence. When the same concept is applied to DAP data (middle), however using DAP points classified as

changes to an inventory resulting from disturbances causing depletions (harvesting, fire, insect defoliation, etc.), as well as changes to the forest causing accretions (growth, silviculture). Bonnor and Magnussen [116] added that depletions and accretions to total forested land from land-use change need also be included. The two main data sources that facilitate updates are information that can be observed and mapped such as harvesting boundaries and fire damage, and those that must be sampled and/or modeled such as permanent sample plots detailing growth, health, and compositional change [116]. In order to perform updates, mapping products and detection of minimum levels of disturbance/growth must have acceptable levels of accuracy, and the frequency and timing of data acquisitions must be established.

Studies assessing the capacity for DAP to perform updating tasks such as Ali-Sisto and Packalen [117] found that DAP was able to detect clearcuts with $98.6 \%$ accuracy, while thinning treatments were $24.1 \%$ accurate. Honkavaara et al. [91] found that DAP was able to detect with $100 \%$ accuracy where more than 10 trees/ha fell as a result of storm conditions. These studies both indicate that DAP is capable of detecting major changes in forests, but cannot accurately detect minor changes such as removal of individual trees from a nondominant canopy layer. ground, data are prone to errors due to lack of ground characterization by DAP. To solve this issue, ground points from $\mathrm{T}_{1}$ ALS data are merged with $\mathrm{T}_{2}$ DAP (bottom) and are used for normalization

Decisions to update are driven by a number of factors, primarily a need for current information to support management planning and decision-making, as well as regulatory requirements and/or reporting obligations [6]. Herein, we demonstrate that DAP data can be useful for both aspects of inventory update: mapping and modeling.

EFI data products are commonly produced at a standard grid-cell size, providing spatially and temporally explicit attribute predictions. These cell-level predictions have the potential to be summarized to stand-level information typically used in forest inventories, while maintaining often unavailable within-stand variability $[15 \cdot, 17,18]$. The inclusion of forest structural data such as height percentiles and crown cover within inventories also provides a means to characterize and segment forested landscapes objectively and provide highresolution predictions of forest attributes. These data can be used to guide forest planning and management decisions, impacting socio-economic and environmental outcomes.

While the currency and spatial completeness of inventories is critical for establishing inventory reliability, the data content of these inventories is fundamental. Photo-interpretation and field measure campaigns are indelible parts of forest inventory frameworks; however, there is opportunity and substantial scientific justification for continued technological 
modernization within inventory programs $[19,118]$. An abundance of remote sensing and forest management research has shown that the integration of structural characterizations of forests improves inventory accuracy, precision, and spatial objectivity $[12,16,20,99 \cdot 0,119,120]$; however, these data should not be viewed as a panacea. Field measurements and validation of remote sensing products will always be essential for ensuring reliability and improving future products [121, 122].

\section{Inventory Update Using DAP Data}

A DAP inventory updating framework would begin with assessing the effectiveness of baseline ALS strata to reflect stand growth as well as management and disturbance activity. Assessing the robustness of DAP data to generate similar strata to ALS should be addressed. Specifically, calibration of canopy closure estimates is important for reliable change detection $[63,99 \bullet \bullet]$.

Following stratification and sample location, field measurement campaigns should be designed to ensure the acquisition of data to support area-based modeling $[15 \cdot, 18]$. Attributes of primary interest have commonly included volume, basal area, height, stem density, and quadratic mean diameter [32, 34••, 42, 96•]. Plot-level point cloud metrics describing height such as height percentiles (e.g., 90th percentile of height), or mean height, and density measures (e.g., percent of points between 10 and $20 \mathrm{~m}$ ) are matched with corresponding field measurement data and used as predictors for parametric or non-parametric predictive models. The use of DAP spectral metrics as predictors, as used in Bohlin et al. [34••] and Puliti et al. [96•], could also be incorporated; however, must be conducted with care due to the potential variation amongst flight imagery, and between successive imagery acquisitions [97, 102•]. Following generation, models are applied wall-to-wall to enable landscape-level mapping of key attributes of interest with known error (Table 1).

\section{DAP Data for Forest Inventory: a Summary of Quantitative Findings}

Preliminary studies looking to determine DAP's effectiveness for area-based attribute predictions used scanned analog photos with GSDs between 0.19 and $0.24 \mathrm{~m}$. Næsset et al. [47] found that mean stand height underestimated true stand height by $5.42 \mathrm{~m}$, and that results were not superior to manual photogrammetric mensuration accuracies. Mean differences were found to be influenced by image-matching parameters, stand age, and site quality. Similarly, St-Onge et al. [83] also found that the accuracy of height estimates were influenced by image-matching parameters, as well as sun illumination, viewing geometry, and the complexity of the forest canopy. Correlations between ALS and DAP in St-Onge et al. [83] were found to be highest in young forests. Results from these pioneering studies helped to establish a foundation for further photogrammetric forest inventory research and highlight how DAP technology has changed.

EFI attribute predictions generated using an ABA and ALS data often meet or exceed the accuracy requirements of forest inventory programs [119]. Furthermore, EFI attribute predictions generated using DAP data in an ABA have been found to be of comparable accuracy to that of ALS data across a range of forest environments, although inventory attribute predictions made using ALS data are consistently more accurate (Table 1). While the studies summarized in Table 1 vary dramatically in their design, parameterization, and implementation, they form a solid basis for recommending the use of DAP data for updating EFIs in the context where an existing ALSderived DTM is available, as well as for continued research into effective acquisition and processing standards.

Locations for comparing ALS and DAP prediction accuracies have predominantly taken place in Scandinavian boreal

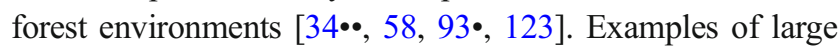
scale studies include Bohlin et al. [124], which compared DAP and ALS attribute modeling over four $10,000 \mathrm{~km}^{2}$ areas in Sweden, Rahlf et al. [125], which examined a range of topographic and positional variables over a $25,000 \mathrm{~km}^{2}$ area in Norway, and Tuominen et al. [126], which assessed the potential contribution of 3D DAP metrics to the Finnish Multi-Source National Forest Inventory (MS-NFI) over $5800 \mathrm{~km}^{2}$. Authors outline the importance of understanding how well results translate to differing forested ecosystems [77]. For example, Vastaranta et al. [99••] achieved high prediction accuracies using DAP in southern Finland; however, they were hesitant to provide recommendations regarding DAP use in mixed-aged, multi-layered stands such as those used in White et al. [42]. Their reasoning was that small variations in landscape-level stand structure resulted in low sample variance, and corresponding strong relationships with ALS and DAP metrics.

\section{Height}

Predictions of variables such as Lorey's mean height $[34 \bullet \bullet, 42$, 93•, 127], mean height $[58,77,99 \bullet \bullet]$, and top height [52] using DAP were consistent across studies (Fig. 5). Pitt et al. [52], which was conducted in central Canadian boreal site, and White et al. [42] in a coastal temperate rainforest found prediction accuracies similar to those found in less complex forests in Scandinavia and Germany, indicating that DAPbased predictions show some robustness to height measurements across forest types. Navarro et al. [88] found that ALS \%RMSE was slightly larger than that of DAP, the only comparison where DAP was found to be more accurate than ALS. 


\section{Density and Stem Diameter}

The prediction of basal area $[42,46,52,68,77,99 \cdot \bullet, 127]$ and mean basal area [34०•], although larger in \%RMSE than height estimates, were consistent across studies and comparable to their ALS counterparts. Iqbal et al. [89•] found that both small- and medium-format sensors were comparable in accuracy to each other, as well as ALS (Fig. 5). Their study found that basal area estimations using DAP (\%RMSE $=14.37$ and 14.27 for short- and medium-format respectively) had greater accuracies than ALS (\%RMSE $=15.26)$ at the stand-level. Greater \%RMSE values are expected for attributes such as basal area, which are dependent on variables such as stem diameter that, as of yet, cannot be directly measured by ALS or DAP. Studies using DAP to model mean diameter [58, 77, 99・•], quadratic mean diameter [127], and diameter distributions [128] found similar results between ALS and DAP estimates (Fig. 5).

The accurate prediction of stem number remains a challenge for both ALS and DAP, especially with low-density point cloud data. Stem number prediction accuracies are variable in the literature (e.g., \%RMSE $=43.7$ for DAP and 35.1 for ALS in Gobakken et al. [93•]; 70.1 for DAP and 63.5 for ALS in Iqbal et al. [89•]; 42.3 for DAP and 31.4 for ALS in Kukkonen et al. [68]). The use of CHMs and other rasterized point cloud metrics are common for individual tree detection approaches [129,130]; however, there is also growing body of research directly using $3 \mathrm{D}$ point cloud data for individual tree detection analyses $[131,132]$. Studies have outlined the importance of high-density point clouds for improving detection accuracy [133], predominantly using ALS data [134-136]; however, the advent of very high-density DAP acquired using UAS data is becoming more prevalent. Methodologies seeking to improve stem number prediction accuracy such as those presented in Tompalski et al. [137] are promising.

\section{Volume}

Comparisons for volume have been most common in the literature (Fig. 5). Estimates of volume for ALS and DAP provide promising and consistent results, and although DAP is shown to have larger \%RMSE, differences are generally small

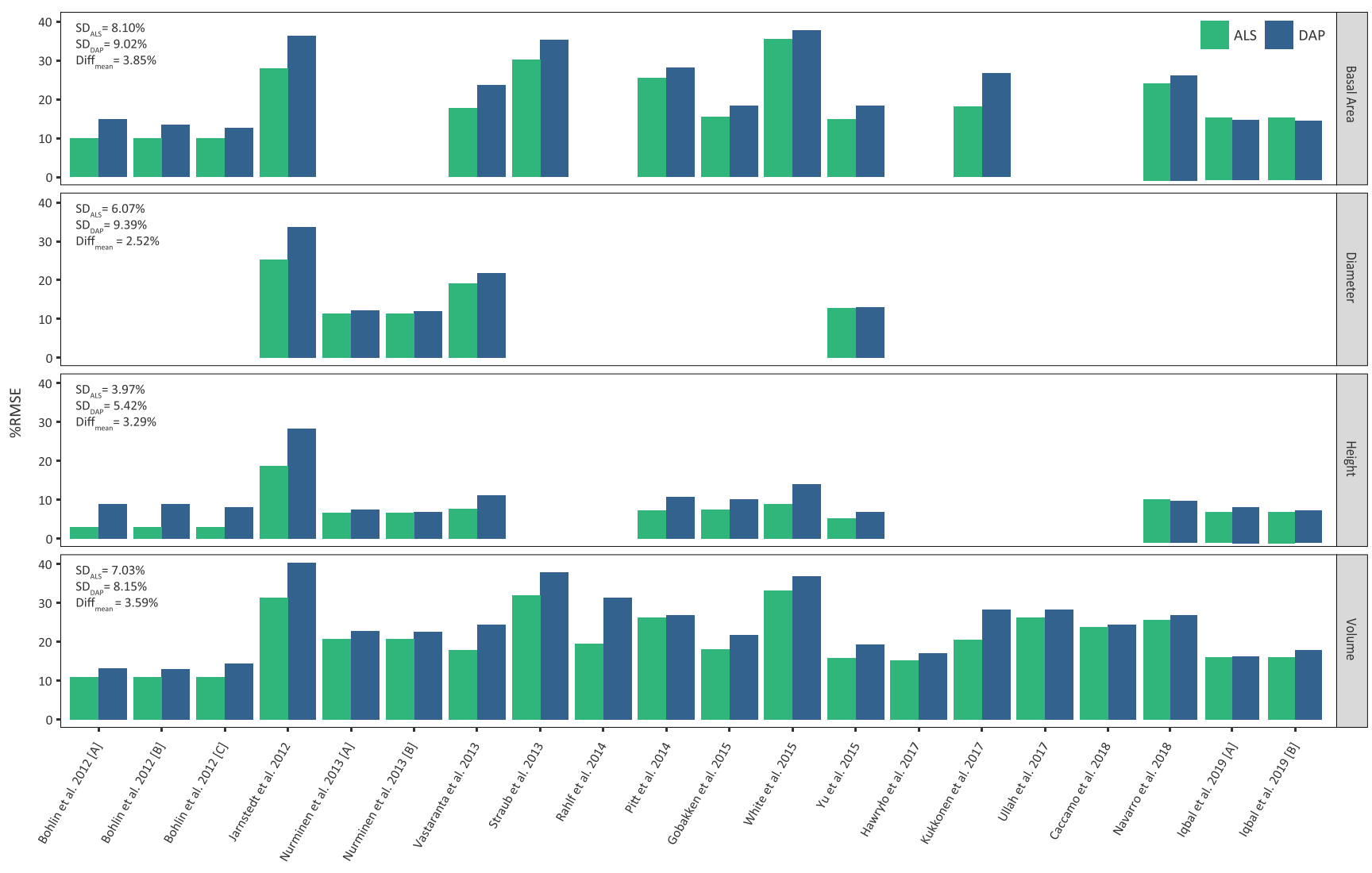

Published literature

Fig. 5 Result of literature review comparing \%RMSE for ALS and DAP for the prediction of volume, height, basal area, and diameter. Standard deviation (SD) of ALS and DAP are presented for each attribute. Mean differences $\left(\right.$ Diff $\left._{\text {mean }}\right)$ between ALS and DAP all indicate the average \%RMSE difference for the attribute being predicted. \%RMSE for DAP was greater for all comparisons except for dominant height in Navarro et al. [88], and basal area in Iqbal et al. [89•]. Blank spaces indicate that a comparison of ALS and DAP for estimating that particular attribute did not take place for that study. Bohlin et al. [34••] [A], [B], [C] as well as Nurminen et al. [58] [A], [B] are separate analyses conducted within the same study with varying acquisition parameters. Iqbal et al. [89•] compared small- $[\mathrm{A}]$ and medium-format $[\mathrm{B}]$ digital sensors 
(Fig. 5). Accurate and consistent volume estimates provide the ability to directly evaluate the economic value of standing timber resources. This information can improve long-term forest planning through maximizing revenue from harvesting operations, and delineating where and when operations should be conducted [23].

\section{Vertical Complexity and Cover}

ALS and DAP characterize forest structure differently, with DAP data primarily characterizing the outer canopy envelope, whereas ALS is capable of characterizing the full vertical distribution of vegetation through the canopy. Studies analyzing these differences have reported that DAP height metrics often provide redundant information resulting from their high degree of correlation. For example, White et al. [42] found that the 10th and 90th percentile of ALS heights in coastal temperate forests were not correlated ( $r=0.33$ ), but that the same metrics were highly correlated for DAP data $(r=0.92)$. Lesser height percentiles are generally found to be situated higher in the canopy for DAP data, as demonstrated by the high level of correlation found by White et al. [42] for DAP mean height and both the 10th and 90th percentiles $(r=0.98)$. Conversely, the greater percentiles are found to be more comparable to their ALS counterparts, indicating that DAP captures the top of canopy well. Nurminen et al. [58] found that image matching with $80 \%$ along-track overlap provided a very dense surface model, however only penetrated to the ground if forest gaps were present. Image matching using $60 \%$ forward overlap in the same study found that matches were predominantly on the outer forest surface indicating that imagery overlap can influence point distribution through the canopy. The density of DAP point clouds $\left(80 \%\right.$ overlap $=155$ points $\mathrm{m}^{-2} ; 60 \%$ overlap $=44$ points $\mathrm{m}^{-2}$ ) in Nurminen et al. [58] were greater than those of ALS (7 points $\mathrm{m}^{-2}$ ), although these greater point densities do not neccesarily translate into greater attribution predictions accuracies [138].

Just as DAP characterization of the outer envelope of the tree canopy limits its ability to provide reliable data on ground surfaces, it also limits its ability to provide information on the vertical distribution of vegetation through the canopy. This limitation could be challenging when considering the transferability of existing ALS area-based models for use with DAP data. In these cases, the point cloud predictors generated from the DAP data may not convey the same structural information as the ALS point cloud predictors used in model development [42]. This highlights a need to develop area-based models with predictor sets that are similar between ALS and DAP data if model transferability is a consideration for inventory update [9].

\section{Cost Considerations}

It is well established that DAP acquisition is considerably cheaper than that of ALS [33••, 43••], while prediction accuracies for basic forest inventory attributes are similar (Fig. 5). Results reported in Kangas et al. [3] support this statement, concluding that the differences in prediction accuracy can be considered negligible from a forest management perspective, especially if the data will be used for 10 years or less, which is the approximate shelf-life of ALS data for supporting forest inventories according to McRoberts et al. [16]. In their study, Kangas et al. [3] assessed the value of ALS and DAP to support harvest scheduling. Both data sources were found to be equally valuable to support decision-making although ALS was more precise. Given that economic losses and accuracy for both technologies were similar, it was recommended that DAP and ALS be considered analogous, and that the decision to acquire either data type should be dependent on availability, experience, project constraints and requirements, and cost rather than geometric properties, point density, or resulting prediction accuracy. Notably, this study did not include the cost of the ALS DTM used to normalize the DAP data. Given that the provision of the ALS DTM is of major importance and motivation for data acquisitions, as well as being critical for DAP normalization, future studies should include its value within economic comparisons. Gobakken et al. [93•] likewise concluded that in a forest inventory context, accuracy alone should not be the only factor considered when choosing between DAP or ALS, but rather the choice must be informed by the utility of the data to support decision-making. It is important to note the substantial computational requirements for processing large areas of DAP data and the potential costs that these requirements may entail.

\section{Research Gaps}

While motivations for the incorporation of DAP into EFI frameworks are justified, there are also logistic and scientific justifications for continued research (Fig. 6).

\section{Acquisition Planning}

- Standardization and benchmarking for acquisition parameters such as flight altitude and GSD, image overlap (along- and across-track), sensor types, and illumination conditions

- Further explore UAS as platforms for cost-effective parameter benchmarking 


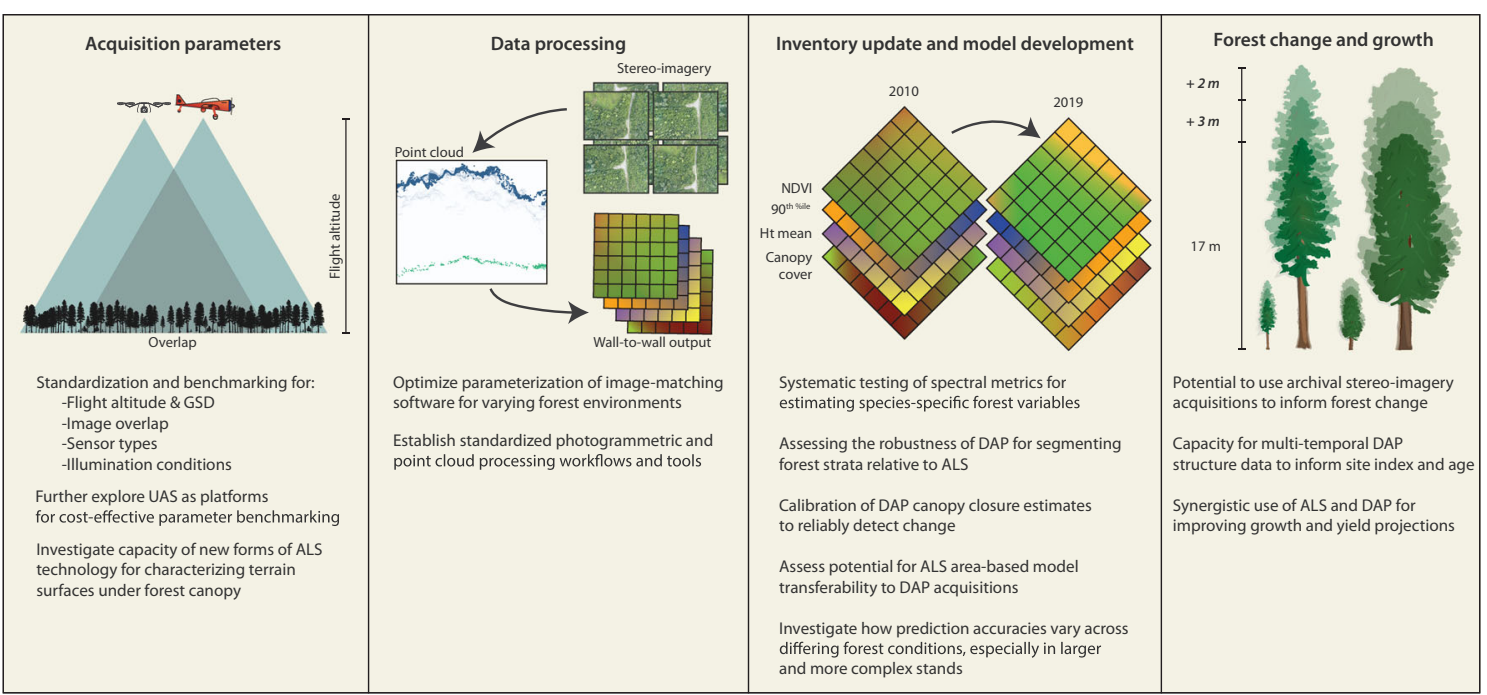

Fig. 6 Summary of where additional research is warranted to improve the potential of DAP in an area-based forest inventory update role

- Investigate capacity of new forms of ALS technology for characterizing terrain surfaces under forest canopy, including single photon systems

An area that requires rigorous sensitivity analysis is understanding how differences in acquisition parameters such as altitude, GSD, and across-track overlap influence the viability of produced point clouds for forest inventory applications. Some such studies have been conducted [34••, 58, 81, 104, 139]; however, more research on this topic is required to outline best practice approaches for different forested ecosystems. Forests with variable vertical and horizontal structure could require acquisition parameters that are different from less complex structures in order to achieve best photogrammetric processing results. Inquiries into which parameters should be used for particular forest types are warranted for the use of DAP as a ubiquitous EFI updating technology.

One of the major inhibitors of conducting parameter benchmarking experiments is high cost. The use of UAS for quickly operationalized, cost-effective, and efficient image acquisition campaigns could help to illuminate how differences in acquisition and point cloud processing parameterization impact variation of area-based outcomes $[23,87]$. Studies focusing on how UAS can be used to establish parametric benchmarking and standardization will help to improve the utility and value of data acquired using conventional manned aircraft. Some parameters such as flight altitude may be more difficult to benchmark due to regulatory restrictions.

The need for an ALS-derived DTM is fundamental. The advent of new ALS technologies such as single photon lidar may enable cost-effective landscape-level characterization of the ground surface with sufficient accuracy to support DAP normalization. Single photon systems have the ability to fly at greater elevations and faster speeds, acquiring ALS data for less cost than currently standard systems [140]. This raises the potential for DAP data to be used to support forest inventory frameworks, especially areas beyond existing EFI boundaries. This would allow EFIs to be used to update previous conventional photo-based inventories and modernize landscape-level forest inventory assessments. Further inquiry into the potential of this technology is needed.

\section{Data Processing}

- Optimize parameterization of image-matching software for varying forest environments

- Establish standardized photogrammetric and point cloud processing workflows and tools

Image-matching algorithms with a focus on forest vegetation reconstruction are needed. Current algorithms, although showing success, could have the potential to be optimized for vegetated environments, helping to further enhance the capacity for area-based predictions using DAP.

Physical characteristics of forests and the local environment that pose problems to photogrammetric point cloud generation also require a greater level of inquiry. Studies have found that shadowing and solar angle/illumination $[50,83$, $92,99 \bullet \bullet, 102 \cdot]$, occlusion from neighboring tree canopy [97], and tree swaying caused by wind [141, 142] have contributed to problems with point cloud generation [104]. Robust analyses into these potential sources of variability in point cloud generation will help to establish best practice conditions, as well as outline potential sources of error, and how to manage them effectively prior to image acquisitions.

Studies that describe how photogrammetric algorithm parameterization can influence point cloud utility for areabased estimates are needed. Iqbal et al. [104] provided a detailed description of how processing parameterization 
within Agisoft Photoscan [143] can influence point cloud outputs and found that differing levels of key point limits, quality, and depth filtering parameters were relatively robust to differences in processing strategies. These results demonstrate that parameterization differences using this particular software do not necessarily adversely influence point cloud utility. Given that processing speed is determined by hardware componentry, these results suggest that parameters with lower processing requirements can be used to generate point clouds that are of utility for area-based outcomes. While promising, analyses that test parameterization in a range of commercially available and open source photogrammetric software's for the purposes of forest inventory applications such as Probst et al. [144] are needed to help establish best practice parametrization routines.

\section{Inventory Update and Model Development}

- Systematic testing of spectral metrics for estimating species-specific forest variables

- Assessing the robustness of DAP for segmenting forest strata relative to ALS

- Calibration of DAP canopy closure estimates to reliably detect change

- Assess potential for ALS area-based model transferability to DAP acquisitions

- Investigate how prediction accuracies vary across differing forest conditions, especially in larger and more complex stands

The provision of spectral information from acquired stereoimagery could play an important role in further deriving qualitative differences in the forested landscape. Investigations of the potential to utilize spectral indices in combination with structural metrics for area-based outcomes should continue.

The integration of these metrics for assessing how well DAP is able to stratify, or delineate forests of relatively homogenous stand structures across landscapes could also be important. Continued assessments of where DAP is successful and limited in stratifying landscapes with similar results to ALS are important steps for more seamless inventory integration. Landscape-level investigations looking to determine DAPs effectiveness for stratifying forest types as well as stand-level assessments to outline canopy closure are needed. Inquiries into characterizing small canopy openings and the influence of shadows and occlusions prevalent in mature forest canopies are of particular importance.

Using DAP to update previously established ALS EFI attributes requires investigation into the potential transferability of area-based models and their coefficients. Relationships between DAP and ALS metrics have been well described [42]; however, details on the potential ubiquity of models across forest types have yet to be conducted in detail. Additionally, further investigations are required regarding how variations in acquisition parameters (e.g., point density, flying altitude, instrumentation, and seasonal effects) could potentially influence model transferability [145]. Rombouts et al. [146] noted that protocols and modeling strategies should account for variations in acquisition parameters as a prerequisite to operational deployment of these approaches.

\section{Forest Change and Growth}

- Potential to use archival stereo-imagery acquisitions to inform on forest change

- Capacity for multi-temporal DAP structure data to inform site index and age

- Synergistic use of ALS and DAP for improving growth and yield projections

While in-depth summaries of forest change and growth are beyond the scope of this review, there have been developments using DAP data to characterize forest change and growth that are worthy of mention. Synergistic uses of ALS and multitemporal DAP acquisitions are showing increasing promise for accurately estimating growth and yield attributes such as height, site index, and age. Analyses capitalizing on the availability of long-term photo archives such as Vastaranta et al. [147], which developed and tested an approach to estimate stand age, and Véga and St-Onge [148•, 149], which showed the potential to estimate and spatially map site index and growth, present promising analytical frameworks. Stepper et al. [150] assessed forest height changes using regularly acquired aerial imagery and suggested that CHMs derived from repeat aerial image surveys can be a viable and cost-effective data source to monitor forest height changes through time. Studies such as these show that the prediction of these attributes can be conducted using available stereo-imagery archives, improving the quality and completeness of forest inventory databases.

A template matching approach proposed in Tompalski et al. [151] for integrating area-based inventories with growth and yield simulators is also promising. Methodologies propose the use of multiple attributes such as volume, basal area, and height to define a growth curve for a spatially explicit area. This spatially explicit method could provide improved and more spatially detailed results than using traditional polygon-based approaches. Adding to this work, Tompalski et al. [32] also looked to determine whether improved growth curve assignments could be realized with the addition of a secondary DAP time-step. Other approaches to assimilating remote sensing data sets such as Nyström et al. [152], which tested the ability to use a DAP-derived CHM time series in combination with growth models, showed promising results for incorporating multiple types of remote sensing data to provide spatial layers of upto-date estimates of forest stand predictions. Further research into data assimilation approaches and multi-temporal modeling of growth and yield curves using DAP data sets is warranted. 


\section{Summary}

DAP data have been proven accurate and cost-effective for the ABA where high accuracy ALS DTMs exist. Analyses comparing area-based estimates for DAP and ALS have found that accuracies can be considered analogous (although ALS data is generally more accurate), with DAP acquisitions being considerably less expensive relative to ALS. These findings highlight the potential role DAP can play in strategic, tactical, and operational forest inventory frameworks in a variety of forested environments. Although successful, we outline that further research and development into DAP acquisition parameters, image-matching algorithms, and point cloud processing streams are needed. Advances in these areas will help to further establish DAP as a logical data source for improving proactive forest management, and fill a gap for technologies capable of cost-effective and accurately updating EFIs.

Acknowledgements This research was funded by the AWARE (Assessment of Wood Attributes using Remote sEnsing) Natural Sciences and Engineering Research Council of Canada Collaborative Research and Development grant to a team led by Nicholas Coops. We thank all anonymous reviewers and journal editorial staff for their efforts in improving the quality of this manuscript. The authors also acknowledge funding support from the Canadian Wood Fibre Centre of the Canadian Forest Service.

\section{Compliance with Ethical Standards}

Conflict of Interest Authors claim no conflicts or competing interests.

Open Access This article is distributed under the terms of the Creative Commons Attribution 4.0 International License (http:// creativecommons.org/licenses/by/4.0/), which permits unrestricted use, distribution, and reproduction in any medium, provided you give appropriate credit to the original author(s) and the source, provide a link to the Creative Commons license, and indicate if changes were made.

\section{References}

Papers of particular interest, published recently, have been highlighted as:

- Of importance

•. Of major importance

1. Forest CD, Forest BCL, Dynamics S, Wiley J. Development following major structure and process II. Stem Exclusion. 1990;1-6.

2. Oliver C., Larson B. Temporal and spatial patterns of tree invasion. For stand Dyn Updat Ed. John Wiley and Sons; 1996. p. 171-93.

3. Kangas A, Gobakken T, Puliti S, Hauglin M, Næsset E. Value of airborne laser scanning and digital aerial photogrammetry data in forest decision making. Silva Fenn. 2018;52:1-19.

4. MacDicken KG. Global Forest Resources Assessment 2015: What, why and how? For Ecol Manage. Elsevier B.V. 2015;352: 3-8. https://doi.org/10.1016/j.foreco.2015.02.006.
5. Barrett F, McRoberts RE, Tomppo E, Cienciala E, Waser LT. A questionnaire-based review of the operational use of remotely sensed data by national forest inventories. Remote Sens Environ. Elsevier B.V. 2016;174:279-89. https://doi.org/10.1016/j.rse.2015.08.029.

6. Gillis MD, Leckie DG. Forest inventory update in Canada. For Chron. 1996;72:138-56.

7. Fridman J, Holm S, Nilsson M, Nilsson P, Ringvall AH, Ståhl G. Adapting National Forest Inventories to changing requirements the case of the Swedish National Forest Inventory at the turn of the 20th century. Silva Fenn. 2014;48:1-29.

8. Franklin SE. Remote sensing for sustainable forest management. 1st ed. Boca Raton: CRC Press; 2001.

9. Stepper C, Straub C, Immitzer M, Pretzsch H. Using canopy heights from digital aerial photogrammetry to enable spatial transfer of forest attribute models: a case study in central Europe. Scand J For Res Taylor \& Francis. 2017;32:748-61.

10. Caccamo G, Iqbal IA, Osborn J, Bi H, Arkley K, Melville G, et al. Comparing yield estimates derived from LiDAR and aerial photogrammetric point-cloud data with cut-to-length harvester data in a Pinus radiata plantation in Tasmania. Aust For. 2018;81:131-41.

11. Goodbody TRH, Coops NC, Hermosilla T, Tompalski P, McCartney G, MacLean DA. Digital aerial photogrammetry for assessing cumulative spruce budworm defoliation and enhancing forest inventories at a landscape-level. ISPRS J Photogramm Remote Sens. 2018;142:1-11 https://www.sciencedirect.com/ science/article/pii/S092427161830145X. Accessed 16 Oct 2018.

12. Wulder MA, Bater C, Coops NC, Hilker T, White J. The role of LiDAR in sustainable forest management. For Chron. 2008;84: 807-26.

13. Næsset E. Predicting forest stand characteristics with airborne scanning laser using a practical two-stage procedure and field data. Remote Sens Environ Elsevier. 2002;80:88-99.

14. Næsset E. Area-based inventory in Norway - from innovation to an operational reality. In: Maltamo M, Næsset E, Vauhkonen J, editors. For Appl Airborne Laser Scanning Concepts Case Stud. Dordrecht, Springer; 2014. p. 215-40. https://doi.org/10.1007/ 978-94-017-8663-8_11.

15. White JC, Wulder MA, Varhola A, Vastaranta M, Coops NC, Cook BD, Woods M. A best practices guide for generating forest inventory attributes from airborne laser scanning data using an area-based approach. CWFC Information Report FI-X-018, Canadian Forest Service, Pacific Forestry Centre: Victoria, BC, Canada. 2013;38pp. Available from: http://cfs.nrcan.gc.ca/ pubwarehouse/pdfs/38945.pdf. Accessed 15 Oct 2018. In depth description of the planning and implementation of the areabased approach to forest attribute prediction using ALS.

16. McRoberts RE, Chen Q, Gormanson DD, Walters BF. The shelflife of airborne laser scanning data for enhancing forest inventory inferences. Remote Sens Environ. Elsevier. 2018;206:254-9. https://doi.org/10.1016/j.rse.2017.12.017.

17. Wulder MA, White JC, Nelson RF, Næsset E, Ørka HO, Coops $\mathrm{NC}$, et al. Lidar sampling for large-area forest characterization: a review. Remote Sens Environ. Elsevier B.V. 2012;121:196-209. https://doi.org/10.1016/j.rse.2012.02.001.

18. White JC, Tompalski P, Vastaranta M, Wulder MA, Saarinen N, Stepper C, Coops NC. A model development and application guide for generating an enhanced forest inventory using airborne laser scanning data and an area-based approach. CWFC Information Report FI-X-018, Canadian Forest Service, Pacific Forestry Centre: Victoria, BC, Canada. 2017;38pp. Available from: http://cfs.nrcan.gc.ca/pubwarehouse/pdfs/38945.pdf. Accessed 10 Oct 2018.

19. McRoberts RE, Tomppo EO. Remote sensing support for national forest inventories. Remote Sens Environ. 2007;110:412-9. 
20. White JC, Coops NC, Wulder MA, Vastaranta M, Hilker T, Tompalski P. Remote sensing technologies for enhancing forest inventories: a review. Can J Remote Sens. 2016;42:619-41.

21. Bechtold WA, Patterson PL. The enhanced forest inventory and analysis program - national sampling design and estimation procedures. 2005. Available from: http://www.treesearch.fs.fed.us/ pubs/20371\%5Cn. http://www.srs.fs.usda.gov/pubs/gtr/gtr_ srs080/gtr srs080.pdf. Accessed 21 Oct 2018.

22. Tompalski P, Coops NC, White JC, Wulder MA. Simulating the impacts of error in species and height upon tree volume derived from airborne laser scanning data. For Ecol Manage. Elsevier B.V. 2014;327:167-77. https://doi.org/10.1016/j.foreco.2014.05.011.

23. Goodbody TRH, Coops NC, Marshall P, Tompalski P, Crawford P. Unmanned aerial systems for precision forest inventory purposes a review and case study. For Chron. 2017;93:71-81.

24. Alam MB, Shahi C, Pulkki R. Economic impact of enhanced forest inventory information and merchandizing yards in the forest product industry supply chain. Socioecon Plann Sci Elsevier Ltd. 2014;48:189-97.

25. Woods M, Pitt D, Penner M, Lim K, Nesbitt D, Etheridge D, et al. Operational implementation of a LiDAR inventory in Boreal Ontario. For Chron. 2011;87:512-28.

26. Guo X, Coops NC, Tompalski P, Nielsen SE, Bater CW, John SJ. Regional mapping of vegetation structure for biodiversity monitoring using airborne lidar data. Ecol Inform. Elsevier B.V. 2017;38:50-61. https://doi.org/10.1016/j.ecoinf.2017.01.005.

27. Mulverhill C, Coops NC, White JC, Tompalski P, Marshall PL, Bailey T. Enhancing the estimation of stem-size distributions for unimodal and bimodal stands in a boreal mixedwood forest with airborne laser scanning data. Forests. 2018;9.

28. Næsset E. Airborne laser scanning as a method in operational forest inventory: status of accuracy assessments accomplished in Scandinavia. Scand J For Res. 2007;22:433-42.

29. Fekety PA, Falkowski MJ, Hudak AT. Temporal transferability of LiDAR-based imputation of forest inventory attributes. Can J For Res. 2015;45:422-35 Available from: http://www.nrcresearchpress. com/doi/10.1139/cjfr-2014-0405. Accessed 13 Oct 2018.

30. Tomppo E, Gschwantner T, Lawrence M, McRoberts RE. National Forest Inventories Pathways for Common Reporting. Netherlands: Springer; 2010.

31. Goodbody TRH, Coops NC, Tompalski P, Crawford P, Day KJ. Updating residual stem volume estimates using ALS- and UAVacquired stereo-photogrammetric point clouds. Int J Remote Sens. 2016;1161.

32. Tompalski P, Coops NC, Wulder MA, Bailey T. Combining multidate airborne laser scanning and digital aerial photogrammetric data for forest growth and yield modelling. Remote Sens. 2018;10:1-21.

33.• White JC, Wulder MA, Vastaranta M, Coops NC, Pitt D, Woods M. The utility of image-based point clouds for forest inventory: a comparison with airborne laser scanning. Forests. 2013;4:518-36 Review paper that summarizes the challeneges and opportunities associated with the use of DAP for forest inventory and identifies key research gaps.

34.• Bohlin J, Wallerman J, Fransson JES. Forest variable estimation using photogrammetric matching of digital aerial images in combination with a high-resolution DEM. Scand J For Res. 2012;27: 692-9 One of the first studies to compare DAP and ALS areabased outcomes. The authors tested the effects of image acquisition parameters (i.e. flight altitude and image overlap) on the area-based estimation of forest variables.

35. Spurr SH. The forests of Itasca in the Nineteenth Century as related to fire published. Ecology. 1954;35:21-5 Available from: https:// www.jstor.org/stable/1931399\%0D. Accessed 26 Oct 2018.

36. McGlone J, Mikhail E, Bethel J, Mullen R. Manual of Photogrammetry. fifth Am Soc Photogramm Remote Seens. 2004.
37. Moessner KE, Survey F. Photo interpretation in Forest inventories. Photogramm Eng. 1953;496-507.

38. Lieut L. Photographing forests from the air. Can For J. 1919;110 2. Available from: http://eco.canadiana.ca/view/oocihm.8_06922_ 106/13?r=0\&s=1. Accessed 04 Nov 2018.

39. Zsilinszky V. The practice of photo interpretation for a forest inventory (Commission VII, Invited paper, Lisbon 1964). Photogrammetria. 1962;19:192-208 Available from: http:// linkinghub.elsevier.com/retrieve/pii/S0031866362800945. Accessed 04 Nov 2018.

40. Leckie DG, Gillis M. Forest inventory in Canada with emphasis on map production. For Chron. 1995;71:74-88.

41. Baltsavias EP. Airborne laser scanning: basic relations and formulas. ISPRS J Photogramm Remote Sens. 1999;54:199-214.

42. White JC, Stepper C, Tompalski P, Coops NC, Wulder MA, White JC, et al. Comparing ALS and image-based point cloud metrics and modelled forest inventory attributes in a complex coastal forest environment. For Multidiscip Dig Publ Instit. 2015;6:3704-32.

43.• Leberl F, Irschara A, Pock T, Meixner P, Gruber M, Scholz S, et al. Point clouds: lidar versus 3D vision. Photogramm Eng Remote Sens. 2010;76:1123-34 Provides state-of-the art synthesis on the capabilities of modern digital camera systems and compares to current ALS capabilities.

44.• Baltsavias EP. A comparison between photogrammetry and laser scanning. ISPRS J Photogramm Remote Sens. 1999;54:83-94 Pioneering comparison of DAP and ALS data, with a comprehensive assessment of trade-offs in mission planning, acquisition, processing, and application of these data.

45. Remondino F, Spera MG, Nocerino E, Menna F, Nex F. State of the art in high density image matching. Photogramm Rec. 2014;29:144-66 Available from: http://doi.wiley.com/10.1111/ phor.12063. Accessed 26 Oct 2018.

46. Straub C, Stepper C, Seitz R, Waser LT. Potential of UltraCamX stereo images for estimating timber volume and basal area at the plot level in mixed European forests. Can J For Res. 2013;43:73141 Available from: http://www.nrcresearchpress.com/doi/10. 1139/cjfr-2013-0125. Accessed 29 Oct 2018.

47. Næsset E. Determination of mean tree height of forest stands by digital photogrammetry. Scand J For Res. 2002;17:446-59.

48. Ullah S, Dees M, Datta P, Adler P, Koch B. Comparing airborne laser scanning, and image-based point clouds by semi-global matching and enhanced automatic terrain extraction to estimate forest timber volume. Forests. 2017;8.

49. Nolan M, Larsen CF, Sturm M. Mapping snow-depth from manned-aircraft on landscape scales at centimeter resolution using structure-from-motion photogrammetry. Cryosph Discuss. 2015;9:333-81 Available from: http://www.the-cryospherediscuss.net/9/333/2015/. Accessed 19 Oct 2018.

50. Stone C, Webster M, Osborn J, Iqbal I. Alternatives to LiDARderived canopy height models for softwood plantations: a review and example using photogrammetry. Aust For. 2016;79:271-82.

51. Pepe M, Fregonese L, Scaioni M. Planning airborne photogrammetry and remote-sensing missions with modern platforms and sensors. Eur J Remote Sens. Taylor \& Francis. 2018;51:412-35. https://doi.org/10.1080/22797254.2018.1444945.

52. Pitt DG, Woods M, Penner M. A comparison of point clouds derived from stereo imagery and airborne laser scanning for the area-based estimation of forest inventory attributes in boreal Ontario. Can J Remote Sens. 2014;40:214-32.

53. Gruen A, Li Z. Automatic DTM generation from three-linescanner (TLS) images. Int Arch Photogramm Remote Sens. 2002;34:131-7.

54. Petrie G, Walker AS. Airborne digital imaging technology: a new overview. Photogramm Rec. 2007;22:203-25. 
55. Haala N, Fritsch D, Stallmann D, Cramer M. On the preformance of digital airborne pushbroom cameras for photogrammetric data processing - a case study. Int Arch Photogramm Remote Sens Part B4 Amsterdam 2000. 2000;XXXIII:324-31. Available from: http://www.isprs.org/proceedings/XXXIII/congress/part4/324 XXXIII-part4.pdf. Accessed 02 Nov 2018.

56. Lemmens M. Digital aerial cameras: system configurations and sensor architectures. GIM Int 2008;22.

57. Kang J, Park J, Kim M, Analysis A, Map D. Digital mapping using aerial digital camera imagery. Int Arch Photogramm Remote Sens Spat Inf Sci. 2008;XXXVII:1275-8.

58. Nurminen K, Karjalainen M, Yu X, Hyyppä J, Honkavaara E. Performance of dense digital surface models based on image matching in the estimation of plot-level forest variables. ISPRS J Photogramm Remote Sens. International Society for Photogrammetry and Remote Sensing, Inc. (ISPRS). 2013;83: 104-15. https://doi.org/10.1016/j.isprsjprs.2013.06.005.

59. Kraus K. Photogrammetrie, 7th edn. In: Verlag W de G, editor. Berlin-New York; 2004.

60. Cramer M, Haala N, Stallmann D. Direct georeferencing using GPS/inertial exterior orientations for photogrammetric applications. IAPRS. 2000;XXXIII.

61. Haala N, Hastedt H, Wolf K, Ressl C, Baltrusch S, Stallmann D, et al. Calibration of directly measured position and attitude by aerotriangulation of three-line airborne imagery. Int Arch Photogramm Remote Sens. 1998;32:23-30.

62. Meng X, Zhang A, Hu S, Sun W, Yang J. A method to align POS data and linear push-broom imaging data. In: Lee G, editor. Adv Autom Robot, vol. 2. Berlin: Springer Berlin Heidelberg; 2012. p. 99-106.

63. Melin M, Korhonen L, Kukkonen M, Packalen P. Assessing the performance of aerial image point cloud and spectral metrics in predicting boreal forest canopy cover. ISPRS J Photogramm Remote Sens. International Society for Photogrammetry and Remote Sensing, Inc. (ISPRS). 2017;129:77-85. https://doi.org/ 10.1016/j.isprsjprs.2017.04.018.

64. Haala N. EuroSDR-project commission 2 - "benchmark on image matching" final report. Austria: Wien; 2014. Available from: http://www.eurosdr.net/sites/default/files/uploaded_files/eurosdr no64_c.pdf. Accessed 02 Nov 2018.

65. Zitová B, Flusser J. Image registration methods: a survey. Image Vis Comput. 2003;21:977-1000.

66. Lowe DG. Distinctive image features from scale-invariant keypoints. Int J Comput Vis. 2004;60:91-110.

67. Remondino F, Menna F. Image-based surface measurement for close-range heritage documentation. Int Arch Photogramm Remote Sens Spat Inf Sci. 2008;XXXVII:199-206.

68. Kukkonen M, Maltamo M, Packalen P. Image matching as a data source for forest inventory - comparison of semi-global matching and next-generation automatic terrain extraction algorithms in a typical managed boreal forest environment. Int J Appl Earth Obs Geoinf. Elsevier B.V. 2017;60:11-21. https://doi.org/10.1016/j. jag.2017.03.012.

69. Remondino F, Del Pizzo S, Kersten TP, Troisi S. Low-cost and open-source solutions for automated image orientation - a critical overview. In: Ioannides M, Fritsch D, Leissner J, Davies R, Remondino F, Caffo R, editors. Prog Cult Herit Preserv. Berlin: Springer Berlin Heidelberg; 2012. p. 40-54.

70. Hirschmüller H. Accurate and efficient stereo processing by semiglobal matching and mutual information. IEEE Comput Soc Conf Comput Vis Pattern Recognit. 2005;2:807-14.

71. Smith MW, Carrivick JL, Quincey DJ. Structure from motion photogrammetry in physical geography. Prog Phys Geogr. $2015 ; 40: 247-75$
72. Baltsavias EP, Gruen A, Eisenbeiss H, Zhang L, Waser LT. Highquality image matching and automated generation of $3 \mathrm{D}$ tree models. Int J Remote Sens. 2008;29:1243-59.

73. Hirschmüller H. Stereo processing by semi-global matching and mutual information. Stereo Process by Semi-Global Matching Mutual Inf. 2008;30:328-41.

74. Dall'Asta E. Semi-global techniques in image matching and change detection with applications to civil and environmental engineering. Università degli Studi di Parma; 2016.

75. Hirschmüller H. Semi-global matching - motivation, developments and applications. Photogramm Week 11. 2011;173-84. Available from: https://elib.dlr.de/73119/. Accessed 19 Oct 2018.

76. Granholm AH, Lindgren N, Olofsson K, Nyström M, Allard A, Olsson $\mathrm{H}$. Estimating vertical canopy cover using dense imagebased point cloud data in four vegetation types in southern Sweden. Int J Remote Sens. Taylor \& Francis. 2017;38:1820 38. https://doi.org/10.1080/01431161.2017.1283074.

77. Järnstedt J, Pekkarinen A, Tuominen S, Ginzler C, Holopainen M, Viitala R, et al. Forest variable estimation using a high-resolution digital surface model. ISPRS J Photogramm Remote Sens. 2012;74:78-84.

78. Zhang B. Next generation automatic terrain extraction (c) 2006. Rochester: Image; 2006.

79. Osborn J, Dell M, Stone C, Iqbal IA, Lacey M, Lucieer A, et al. Photogrammetry for forest inventory: planning guidelines. 2017. Available from: http://www.fwpa.com.au/images/resources/2017/Photogrammetry_for_Forest_Inventory_Planning_Guide PNC326-1314.pdf. Accessed 24 Oct 2018.

80. Honkavaara E, Arbiol R, Markelin L, Martinez L, Cramer M, Bovet S, et al. Digital airborne photogrammetry-a new tool for quantitative remote sensing?-a state-of-the-art review on radiometric aspects of digital photogrammetric images. Remote Sens. 2009:1:577-605.

81. Granholm AH, Olsson H, Nilsson M, Allard A, Holmgren J. The potential of digital surface models based on aerial images for automated vegetation mapping. Int J Remote Sens. Taylor \& Francis. 2015;36:1855-70. https://doi.org/10.1080/01431161.2015. 1029094.

82. Waser LT, Baltsavias EP, Ecker K, Eisenbeiss H, FeldmeyerChriste E, Ginzler C, et al. Assessing changes of forest area and shrub encroachment in a mire ecosystem using digital surface models and CIR aerial images. Remote Sens Environ. 2008;112: 1956-68.

83. St-Onge B, Véga C, Fournier RA, Hu Y, Vega C, Fournier RA, et al. Mapping canopy height using a combination of digital stereo-photogrammetry and lidar. Int J Remote Sens. 2008;29: 3343-64.

84. Hulet A, Roundy BA, Petersen SL, Bunting SC, Jensen RR, Roundy DB. Utilizing national agriculture imagery program data to estimate tree cover and biomass of $\mathrm{Pi}$ non and Juniper Woodlands. Rangel Ecol Manag. Elsevier Masson SAS. 2014;67:563-72. https://doi.org/10.2111/REM-D-13-00044.1.

85. Muurinen L, Oksanen J, Vanha-Majamaa I, Virtanen R. Legacy effects of logging on boreal forest understorey vegetation communities in decadal time scales in northern Finland. For Ecol Manage. Elsevier; 2019;436:11-20. Available from: https://www. sciencedirect.com/science/article/pii/S0378112718312295. Accessed 17 Jan 2019.

86. Ginzler C, Hobi ML. Countrywide stereo-image matching for updating digital surface models in the framework of the Swiss national forest inventory. Remote Sens. 2015;7:4343-70.

87. Puliti S, Ørka HO, Gobakken T, Næsset E. Inventory of small forest areas using an unmanned aerial system. Remote Sens. 2015;7:9632-54.

88. Navarro JA, Fernández-Landa A, Tomé JL, Guillén-Climent ML, Ojeda JC. Testing the quality of forest variable estimation using 
dense image matching: a comparison with airborne laser scanning in a Mediterranean pine forest. Int J Remote Sens. Taylor \& Francis. 2018;39:4744-60. https://doi.org/10.1080/01431161. 2018.1471551.

89. Iqbal IA, Musk RA, Osborn J, Stone C, Lucieer A. A comparison of area-based forest attributes derived from airborne laser scanner, small-format and medium-format digital aerial photography. Int $\mathbf{J}$ Appl Earth Obs Geoinf. Elsevier; 2019;76:231-41. https://doi. org/10.1016/j.jag.2018.12.002. Demonstrated robustness of DAP across small and medium format cameras.

90. Lim K, Hopkinson C, Treitz P. Examining the effects of sampling point densities. For Chron. 2008;84:876-85.

91. Honkavaara E, Litkey P, Nurminen K. Automatic storm damage detection in forests using high-altitude photogrammetric imagery. Remote Sens. 2013;5:1405-24.

92. Honkavaara E, Markelin L, Rosnell T, Nurminen K. Influence of solar elevation in radiometric and geometric performance of multispectral photogrammetry. ISPRS J Photogramm Remote Sens. International Society for Photogrammetry and Remote Sensing, Inc. (ISPRS). 2012;67:13-26. https://doi.org/10.1016/j.isprsjprs. 2011.10.001.

93. Gobakken T, Bollandsås OM, Næsset E. Comparing biophysical forest characteristics estimated from photogrammetric matching of aerial images and airborne laser scanning data. Scand J For Res. 2015;30:73-86 One of the few studies to compare ALS and DAP area-based outcomes at the stand level as well as the plot-level.

94. Tanhuanpää T, Saarinen N, Kankare V, Nurminen K, Vastaranta M, Honkavaara E, et al. Evaluating the performance of highaltitude aerial image-based digital surface models in detecting individual tree crowns in mature boreal forests. Forests. 2016;7.

95. Lemaire C. Aspects of the DSM production with high resolution images. Int Arch Photogramm Remote Sens Spat Inf Sci. 2005;XXXVII:1143-6.

96. Puliti S, Gobakken T, Ørka HO, Næsset E. Assessing 3D point clouds from aerial photographs for species-specific forest inventories. Scand J For Res. Taylor \& Francis; 2017;32:68-79. Comparison of ALS and DAP species-specific applications, as well as testing of image overlap on area-based outcomes.

97. St-Onge B, Audet F-A, Bégin J. Characterizing the height structure and composition of a boreal forest using an individual tree crown approach applied to photogrammetric point clouds. Forests. 2015;6:3899-922 Available from: http://www.mdpi.com/19994907/6/11/3899/. Accessed 27 Oct 2018.

98. White JC, Tompalski P, Coops NC, Wulder MA. Comparison of airborne laser scanning and digital stereo imagery for characterizing forest canopy gaps in coastal temperate rainforests. Remote Sens Environ. Elsevier. 2018;208:1-14. https://doi.org/10.1016/j. rse.2018.02.002.

99.• Vastaranta M, Wulder MA, White JC, Pekkarinen A, Tuominen S, Ginzler C, et al. Airborne laser scanning and digital stereo imagery measures of forest structure: comparative results and implications to forest mapping and inventory update. Can J Remote Sens. 2013;39:382-95 A comprehensive comparison of both ALS and DAP point clouds metrics as well as investigating the use of ALS and DAP in a change detection/inventory update scenario.

100. Haala N, Hastedt H, Wolf K, Ressl C, Baltrusch S. Digital photogrammetric camera evaluation - generation of digital elevation models. Photogramm Fernerkundung Geoinf. 2010;2010:99-115 Available from: http://openurl.ingenta.com/content/xref?genre= article \&issn $=1432-8364 \&$ volume $=2010 \&$ issue $=2 \&$ spage $=99$. Accessed 27 Oct 2018.

101. Frey J, Kovach K, Stemmler S, Koch B. UAV photogrammetry of forests as a vulnerable process. A sensitivity analysis for a structure from motion RGB-image pipeline. Remote Sens. 2018;10.
102. Rahlf J, Breidenbach J, Solberg S, Næsset E, Astrup R. Digital aerial photogrammetry can efficiently support large-area forest inventories in Norway. Forestry. 2017;90:710-8 First study to look at a large-area application of DAP for forest inventory.

103. Stone C, Mohammed C. Application of remote sensing technologies for assessing planted forests damaged by insect pests and fungal pathogens: a review. Curr For Rep. 2017;3:75-92.

104. Iqbal IA, Osborn J, Stone C, Lucieer A, Dell M, McCoull C. Evaluating the robustness of point clouds from small format aerial photography over a Pinus radiata plantation. Aust For. Taylor \& Francis. 2018;81:162-76. https://doi.org/10.1080/00049158. 2018.1482799 .

105. The American Society for Photogrammetry \& Remote Sensing. LAS 1.4 Draft Specification. ASPRS, Am Soc Photogramm Remote Sens. 2011;1-18. Available from: http://www.asprs.org/ a/society/committees/lidar/LAS_1-4_R6.pdf. Accessed 15 Oct 2018.

106. Isenburg M. LASzip: lossless compression of LiDAR data. Photogramm Eng Remote Sens. 2013;79:209-17.

107. Westoby MJ, Brasington J, Glasser NF, Hambrey MJ, Reynolds JM. "Structure-from-motion" photogrammetry: a low-cost, effective tool for geoscience applications. Geomorphology. Elsevier B.V. 2012;179:300-14. https://doi.org/10.1016/j.geomorph.2012. 08.021 .

108. Tomaštík J, Mokroš M, Saloš S, Chudỳ F, Tunák D, Saloň Š, et al. Accuracy of photogrammetric UAV-based point clouds under conditions of partially-open forest canopy. Forests. Multidisciplinary Digital Publishing Institute. 2017;8:151.

109. Goodbody TRH, Coops NC, Hermosilla T, Tompalski P, Pelletier G. Vegetation phenology driving error variation in digital aerial photogrammetrically derived terrain models. Remote Sens. 2018;10:1554 Available from: http://www.mdpi.com/2072-4292/ 10/10/1554. Accessed 18 Oct 2018.

110. Corona P. Consolidating new paradigms in large-scale monitoring and assessment of forest ecosystems. Environ Res. Elsevier. 2016;144:8-14. https://doi.org/10.1016/j.envres.2015.10.017.

111. Holopainen M, Vastaranta M, Hyyppä J. Outlook for the next generation's precision forestry in Finland. Forests. 2014;5: 1682-94.

112. Økseter R, Bollandsås OM, Gobakken T, Næsset E. Modeling and predicting aboveground biomass change in young forest using multi-temporal airborne laser scanner data. 2015;30:458-69.

113. Tompalski P, Coops NC, White JC, Wulder MA, Pickell PD. Estimating forest site productivity using airborne laser scanning data and Landsat time series. Can J Remote Sens. 2015;41:232-45.

114. Hilker T, Wulder MA, Coops NC. Update of forest inventory data with lidar and high spatial resolution satellite imagery. Can J Remote Sens. 2008;34:5-12 Available from: http://www.csa. $\mathrm{com} /$ partners/viewrecord.php?requester=gs\&amp;collection= TRD\&amp;recid=13921044CE. Accessed 13 Oct 2018.

115. Bolton DK, White JC, Wulder MA, Coops NC, Hermosilla T, Yuan X. Updating stand-level forest inventories using airborne laser scanning and Landsat time series data. Int J Appl Earth Obs Geoinf. Elsevier; 2018;66:174-83. Available from: http:// linkinghub.elsevier.com/retrieve/pii/S0303243417302751. Accessed 17 Nov 2018.

116. Bonnor GM, Magnussen S. Forest inventories in Canada: a framework for change. For Chron. 1987;63:193-8.

117. Ali-Sisto D, Packalen P. Forest change detection by using point clouds from dense image matching together with a LiDARderived terrain model. IEEE J Sel Top Appl Earth Obs Remote Sens. 2017;10:1197-206.

118. Holopainen M, Vastaranta M, Karjalainen M, Karila K, Kaasalainen S, Honkavaara E. Forest inventory attribute estimation using airborne laser scanning, aerial stereo imagery, radargrammetry and interferometry - Finnish experiences of the 
3d techniques. ISPRS Ann Photogramm Remote Sens Spat Inf Sci. 2015;2:25-7.

119. Magnussen S, Næsset E, Gobakken T, Frazer G. A fine-scale model for area-based predictions of tree-size-related attributes derived from LiDAR canopy heights. Scand J For Res. 2012;27: $312-22$.

120. van Leeuwen M, Nieuwenhuis M. Retrieval of forest structural parameters using LiDAR remote sensing. Eur J For Res. 2010;129:749-70.

121. Frazer GW, Magnussen S, Wulder MA, Niemann KO. imulated impact of sample plot size and co-registration error on the accuracy and uncertainty of LiDAR-derived estimates of forest stand biomass. Remote Sens Environ. Elsevier Inc. 2011;115:636-49. https://doi.org/10.1016/j.rse.2010.10.008.

122. Strunk J, Temesgen H, Andersen HE, Flewelling JP, Madsen L. Effects of lidar pulse density and sample size on a model-assisted approach to estimate forest inventory variables. Can J Remote Sens. 2012;38:644-54.

123. Rahlf J, Breidenbach J, Solberg S, Astrup R. Forest parameter prediction using an image-based point cloud: a comparison of semi-ITC with ABA. Forests. 2015;6:4059-71.

124. Bohlin J, Bohlin I, Jonzén J, Nilsson M. Mapping forest attributes using data from stereophotogrammetry of aerial images and field data from the national forest inventory. Silva Fenn. 2017;51:1-18.

125. Rahlf J. Forest resource mapping using 3D remote sensing: combining national forest inventory data and digital aerial photogrammetry. 2017.

126. Tuominen S, Pitkänen T, Balázs A, Kangas A. Improving Finnish multi-source national forest inventory by $3 \mathrm{D}$ aerial imaging. Silva Fenn. 2017;51:1-21

127. Yu X, Hyyppä J, Karjalainen M, Nurminen K, Karila K, Vastaranta M, et al. Comparison of laser and stereo optical, SAR and InSAR point clouds from air- and space-borne sources in the retrieval of forest inventory attributes. Remote Sens. 2015;7: 15933-54.

128. Penner M, Woods M, Pitt DG. A comparison of airborne laser scanning and image point cloud derived tree size class distribution models in Boreal Ontario. Forests. 2015;6:4034-54.

129. Ene L, Næsset E, Gobakken T. Single tree detection in heterogeneous boreal forests using airborne laser scanning and area-based stem number estimates. Int J Remote Sens. 2012;33:5171-93.

130. Popescu SC, Wynne RH, Nelson RH. Estimating plot-level tree heights with LIDAR: local filtering with a canopy-height based variable window size. Comput Electron Agric. 2002;37:71-95.

131. Li W, Guo Q, Jakubowski MK, Kelly M. A new method for segmenting individual trees from the Lidar Point Cloud Wenkai. Photogramm Eng Remote Sens. 2012;78:75-84.

132. Lindberg E, Holmgren J. Individual tree crown methods for $3 \mathrm{D}$ data from remote sensing. Curr For Reports. 2017;3:19-31.

133. Wang Y, Hyyppa J, Liang X, Kaartinen H, Yu X, Lindberg E, et al. International benchmarking of the individual tree detection methods for modeling 3-D canopy structure for silviculture and forest ecology using airborne laser scanning. IEEE Trans Geosci Remote Sens. 2016;54:5011-27.

134. Lee H, Slatton KC, Roth BE, Cropper WP. Adaptive clustering of airborne LiDAR data to segment individual tree crowns in managed pine forests. Int J Remote Sens. 2010;31:117-39.

135. Yao W, Wei Y. Detection of 3-d individual trees in urban areas by combining airborne lidar data and imagery. IEEE Geosci Remote Sens Lett IEEE. 2013;10:1355-9.

136. Lee J, Cai X, Lellmann J, Dalponte M, Malhi Y, Butt N, et al. Individual tree species classification from airborne multisensor imagery using robust PCA. IEEE J Sel Top Appl Earth Obs Remote Sens. 2016;9:2554-67.
137. Tompalski P, Coops NC, White JC, Wulder MA. Enriching ALSderived area-based estimates of volume through tree-level downscaling. Forests. 2015;6:2608-30.

138. Treitz P, Lim K, Woods M, Pitt D, Nesbitt D, Etheridge D. LiDAR sampling density for forest resource inventories in Ontario. Canada Remote Sens. 2012;4:830-48.

139. Puliti S. Use of photogrammetric 3D data for forest inventory. 2017.

140. Wästlund A, Holmgren J, Lindberg E, Olsson H. Forest variable estimation using a high altitude single photon lidar system. Remote Sens. 2018;10:1442 Available from: http://www.mdpi. com/2072-4292/10/9/1442. Accessed 18 Nov 2018

141. Dandois JP, Ellis EC. Remote sensing of vegetation structure using computer vision. Remote Sens. 2010;2:1157-76 Available from: http://www.scopus.com/inward/record.url?eid=2-s2.0$84860407983 \& \mathrm{p}$ a r t n e r I D $=40 \& \mathrm{~m} \mathrm{~d} 5=$ 983b00c56ec3f3c3e79677ef5c767ce4. Accessed 18 Oct 2018.

142. Näsi R, Honkavaara E, Lyytikäinen-Saarenmaa P, Blomqvist M, Litkey P, Hakala T, et al. Using UAV-based photogrammetry and hyperspectral imaging for mapping bark beetle damage at treelevel. Remote Sens. 2015;7:15467-93 Available from: www. mdpi.com/journal/remotesensing.

143. Agisoft. Agisoft PhotoScan Professional Edition. St. Petersburg, Russia; 2018.

144. Probst A, Gatziolis D, Strigul N. Intercomparison of photogrammetry software for three-dimensional vegetation modelling. R Soc Open Sci. 2018;5.

145. Fekety PA, Falkowski MJ, Hudak AT, Jain TB, Evans JS Transferability of lidar-derived basal area and stem density models within a Northern Idaho Ecoregion. Can J Remote Sens. Taylor \& Francis; 2018;44:131-43. Available from: https://www. tandfonline.com/doi/full/10.1080/07038992.2018.1461557. Accessed 16 Nov 2018.

146. Rombouts J, Ferguson IS, Leech JW. Campaign and site effects in LiDAR prediction models for site-quality assessment of radiata pine plantations in South Australia. Int J Remote Sens. 2010;31: 1155-73.

147. Vastaranta M, Niemi M, Wulder MA, White JC, Nurminen K, Litkey $\mathrm{P}$, et al. Forest stand age classification using time series of photogrammetrically derived digital surface models. Scand J For Res. 2016;31:194-205.

148. Véga C, St. Onge B. Height growth reconstruction of a boreal forest canopy over a period of 58 years using a combination of photogrammetric and lidar models. Remote Sens Environ. 2008;112:1784-94 A pioneering study that demonstrated the capacity to combine the use of DAP and ALS for monitoring growth over time.

149. Véga C, St-Onge B. Mapping site index and age by linking a time series of canopy height models with growth curves. For Ecol Manag. 2009;257:951-9.

150. Stepper C, Straub C, Pretzsch H. Assessing height changes in a highly structured forest using regularly acquired aerial image data. Forestry. 2014;88:304-16.

151. Tompalski P, Coops NC, White JC, Wulder MA. Enhancing forest growth and yield predictions with airborne laser scanning data: increasing spatial detail and optimizing yield curve selection through template matching. Forests. 2016;7:1-20.

152. Nyström M, Lindgren N, Wallerman J, Grafström A, Muszta A, Nyström K, et al. Data assimilation in forest inventory: first empirical results. Forests. 2015;6:4540-57.

Publisher's Note Springer Nature remains neutral with regard to jurisdictional claims in published maps and institutional affiliations. 